\title{
Heat Management Strategy Trade Study
}

Nick Soelberg

Steve Priebe

Dirk Gombert

Ted Bauer

September 2009

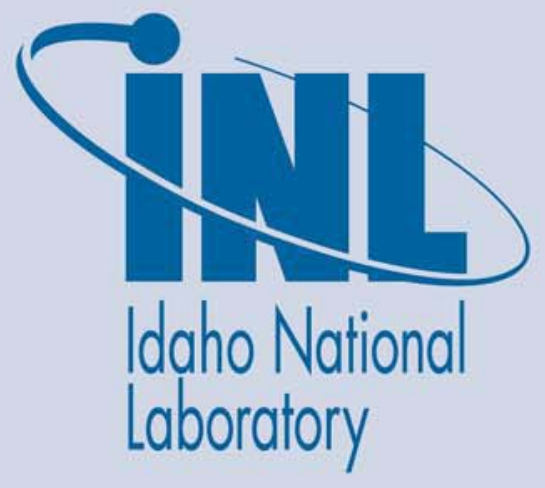

The INL is a U.S. Department of Energy National Laboratory operated by Battelle Energy Alliance 
INL/EXT-09-16708

\title{
Heat Management Strategy Trade Study
}

\author{
Nick Soelberg \\ Steve Priebe \\ Dirk Gombert \\ Ted Bauer ${ }^{1}$ \\ ${ }^{1}$ Argonne National Laboratory
}

September 2009

\section{Idaho National Laboratory \\ Idaho Falls, Idaho 83415}

http://www.inl.gov

Prepared for the

U.S. Department of Energy

Office of Nuclear Energy

Under DOE Idaho Operations Office

Contract DE-AC07-05ID14517 


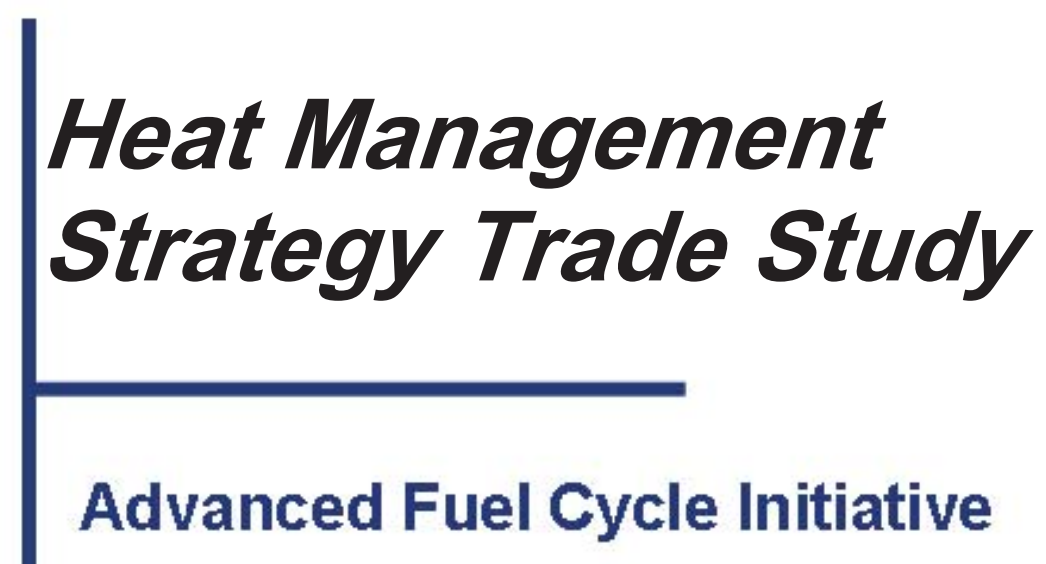

Prepared for

U.S. Department of Energy Systems Analysis Campaign

Nick Soelberg, Steve Priebe, Dirk Gombert Idaho National Laboratory

Ted Bauer

Argonne National Laboratory

September 15, 2009

AFCI-SYSA-PMO-MI-DV-2009-000169

INL/EXT-09-16708 


\section{DISCLAIMER}

This information was prepared as an account of work sponsored by an agency of the U.S. Government. Neither the U.S. Government nor any agency thereof, nor any of their employees, makes any warranty, expressed or implied, or assumes any legal liability or responsibility for the accuracy, completeness, or usefulness, of any information, apparatus, product, or process disclosed, or represents that its use would not infringe privately owned rights. References herein to any specific commercial product, process, or service by trade name, trade mark, manufacturer, or otherwise, does not necessarily constitute or imply its endorsement, recommendation, or favoring by the U.S. Government or any agency thereof. The views and opinions of authors expressed herein do not necessarily state or reflect those of the U.S. Government or any agency thereof. 


\section{SUMMARY}

Several studies have been performed in recent years to evaluate options for managing wastes generated from recycling spent nuclear fuel (SNF). This Heat Management Trade Study has been performed in 2008-2009 to expand on these prior studies in continued efforts to analyze and evaluate options for cost-effectively managing SNF reprocessing wastes.

The primary objective of the Heat Management Trade Study was to evaluate strategies to most costeffectively increase the loading of waste in the repository without exceeding the temperature limits. Dose and volume limits are not specifically considered in this study, although dose is discussed qualitatively. The Yucca Mountain waste repository thermal limits, used in prior studies and in this study prior to February 2009 (when plans for the Yucca Mountain repository were stopped pending the evaluation of other alternatives for handling SNF in the U.S.) continued to be used in this study because (a) there are no thermal limits for other potential repositories to base this study on, and (b) the results, based on the Yucca Mountain characteristics, are still (most likely) instructive and illustrative regardless of the eventual HLW repository situation. This objective is based on the premise that the legislated 70,000 MT limit for Yucca Mountain in the Nuclear Waste Policy Act (NWPA) could be increased or eliminated, such as could occur when a second repository becomes available. Parameters that were varied in this study include:

- Age of the SNF prior to reprocessing and prior to emplacement in the repository

- Uranium, plutonium, and minor actinide (MA) separation from the SNF for recycle, and separation efficiencies

- Fuel value of the recycled Pu and MA

- Length of time that active ventilation is employed in the repository.

This trade study is based on several assumptions about SNF, separations processes, and repository requirements. The results of the trade study have some limitations that should be considered when using the results. These assumptions and limitations are itemized in this report. The most important ones are:

- The Yucca Mountain Total System Performance Assessment (TSPA) is based on a number of assumptions relative to geology and climate, repository design, SNF and high-level waste (HLW) types and relative amounts, as well as a tremendous amount of experimental data to characterize the durability of the disposed materials. The results of the study and how it applies to other repository environments and disposal inventories can thus only indicate trends. A more quantitative result, which relies on more precise quantification of potential radionuclides release, would require modeling, similar to the TSPA, for an inventory derived from large-scale reprocessing resulting in mostly HLW with only a limited amount of SNF in a particular environment.

- A single borosilicate glass waste form was selected for simplicity in this analysis rather than considering a suite of waste forms for each of the separation processes. The use of a glass waste form results in limits imposed on the composition and waste loading to ensure that the glass is durable for long time periods. The highest possible waste loading for acceptable glass durability is the lowest waste loading calculated based on heat generation and waste constituent solubility in the glass to ensure that the glass contains only a single major vitrified phase and does not devitrify over time. Other waste forms may have different waste loading and composition limits.

Conclusions of this trade study include:

- Both short-term and long-term heat generation can limit geological repository SNF and HLW loadings by affecting the temperature of the waste form, waste package, or the rock, all of which have temperature limits. Exceeding any of these temperature limits could jeopardize the intended isolation of the waste from the environment. Different assumed cases of (a) SNF aging prior to emplacement, 
(b) efficiencies of U, Pu, minor actinide (MA), and undissolved solids (UDS) separations, and (c) repository ventilation following emplacement, can increase the repository loading by reducing (or removing) heat generated by the emplaced waste, until any one of several thermal or waste loading limits are reached - the borosilicate glass waste form temperature, the drift wall temperature, the middrift rock temperature, or chemistry (waste loading) limits for the glass. The repository loading efficiency can be increased by about 1.3 times through SNF aging and repository ventilation, without any SNF reprocessing. The limiting factor in cases without any SNF reprocessing is the long-term temperature of the mid-drift rock temperature, which is exceeded at higher repository loadings without reprocessing the SNF to remove most or all of the long-lived $\mathrm{Pu} / \mathrm{Am}$.

- The repository loading efficiency can be increased above 1.3 times with combinations of separations efficiencies, SNF aging prior to waste emplacement, and repository cooling after emplacement. Cases with $\mathrm{Pu}, \mathrm{Am}, \mathrm{MA}$, and UDS removal, SNF aging, and repository cooling at reasonable maximum values could increase the repository loading efficiency to about 3 times when borosilicate glass is assumed to be a single waste form. Higher loading efficiencies are limited by the chemistry of the glass, not heat generation. Increasing the loading efficiency above about 3 times is only possible with additional changes, such as changing the waste form to allow higher waste loadings or modifying the repository design or thermal limits.

- Separating Pu and the MA (for recycle) reduces the long-term heat impact on the repository. If the borosilicate glass waste loading limits are changed, then higher repository waste loading efficiencies of up to 80 times are possible using a combined total 300-year SNF aging and ventilation time, plus 99.9\% removal of $\mathrm{Pu}$ and Am. In this case, the limiting factor is the long-term mid-drift rock temperature. Smaller loading increases are possible with shorter aging and ventilation times and lessefficient $\mathrm{Pu}$ and $\mathrm{Am}$ removal.

- Recycling Pu and MA provides economic value in the fuel value of recycled fuel, along with increased repository loadings. The reduction in the glass amount reduces the costs of vitrification and waste disposal. Using these cost metrics, combined with aging the SNF for up to 40 years, provides an annual cost benefit of up to about $\$ 250$ million per year for an aqueous SNF separations facility operating at $800 \mathrm{MTIHM} /$ year, or about $\$ 310,000 /$ MTIHM processed. This analysis accounts for about $12 \%$ decrease in the Pu due to decay, which is almost entirely offset by the increase in the MA value, so the net loss in the total fuel value that includes the MA is only about $1.7 \%$ over 40 years. The fuel value can help offset the SNF separations costs, which have not been included in this analysis at this time. Other factors not considered in this analysis are (a) the time value of money, (b) costs for alternative UDS management, and (c) future economics of new uranium or other new fuel resources that would affect the future value of recycled fuel.

- In addition to decreasing the number of canisters to be disposed, thereby reducing the cost for treatment and disposal, aging SNF prior to reprocessing lowers the radiation levels of the SNF. Aged SNF has lower radioactivity than greener SNF. This lowers the amount of shielding needed for temporary storage, transport, and processing facilities, lowers the dose hazard to personnel, and lowers the amount of damaging radiation to which equipment is exposed. The lower radiation levels may result in handling, storage, processing, and transportation cost savings that are not included in this study.

- Aging SNF prior to reprocessing, or recovering some groups of radionuclides from SNF during reprocessing, can lower the remaining radiotoxicity of the waste when emplaced in a repository. Current calculations set the dose risk from direct disposal of SNF in the Yucca Mountain repository at $0.24 \mathrm{mrem} /$ year, which is about 60 times lower than the allowable Yucca Mountain limit of 15 $\mathrm{mrem} / \mathrm{year}$. Thus, the dose risk is not the limiting factor for the amount of direct-disposed SNF that is regulatorily allowed to be disposed in Yucca Mountain. Holding all other factors that can affect the dose risk constant, SNF aging or separations processes can theoretically increase the loading 
efficiency by about 60 times before reaching the dose risk limit. However, SNF separations removes some of the radiotoxicity in the remaining waste by removing some of those elements that contribute to the radiotoxicity (Piet 2009). This would further increase the margin of safety for the dose risk. The dose risk would need to be evaluated in more detail in heat management cases that result in potential increases in the repository loading above 60 times.

- Spent nuclear fuel contains several radioactive fission products that tend to evolve into gaseous streams during spent fuel reprocessing. Prior analyses have shown that C-14-laden gaseous species should not require any emissions control and still meet expected regulatory limits that would be based on dose to the public. In addition, this study indicates that SNF aging prior to separations between 30 and 70 years could eliminate the need to control Kr-85 emissions; aging between about 90 and 140 years could eliminate the need to control H-3 emissions. Aging the SNF for these durations could simplify the reprocessing facility, and could simplify the current integrated waste management strategy that includes waste streams for both $\mathrm{Kr}-85$ and H-3. Control of air emissions of I-129 during reprocessing is expected to be required regardless of SNF aging times.

This study has augmented the results of prior studies through additional analyses of SNF aging, separations, and repository ventilation times. Analysis tools were developed for evaluating these parameters using metrics including costs and repository loading factors. Results show that any one of several different, and seemingly unrelated, parameters such as short-term heat generation, long-term heat generation, waste form temperature limits, repository temperature limits, waste chemistry limits, and dose limits can restrict repository waste loadings. The dominance of any of these parameters can depend on the assumed scenarios. All of these parameters need to be considered in future radioactive waste management and disposal evaluations. Results also suggest that the value of recycled fuel be considered in evaluations of spent fuel reprocessing.

These analyses have so far been restricted to LWR spent fuels, borosilicate glass waste forms, and the Yucca Mountain repository requirements. These analyses have not considered (a) SNF temporary storage and separations costs in the economic evaluations; (b) the time value of money; (c) future supply and demand of raw materials for nuclear fuels; (d) management, potential recycle, and metrics of components of SNF such as the UDS, hardware, and hulls; and (e) management of radioactive wastes from operations and maintenance of a reprocessing facility. Some of these can be very important issues that should be considered in future analyses.

Future analyses should include:

- Consideration of potential thermal and radiotoxicity limits that might occur for various candidate geological repository configurations besides Yucca Mountain.

- Evaluations of SNF management for fast reactors and recycled fuel reactors including Pu and MA transmutation reactors.

- Electrochemical (Echem) separations.

- More definitive separations factors for aqueous and Echem separations based on empirical results (when available) or more detailed modeling.

- Alternative waste forms besides borosilicate glass that might have higher waste loading capabilities based on higher temperature and chemistry tolerance.

- Consideration of waste forms tailored for alternative geological repository characteristics for maximum waste immobilization.

- Evaluation of cost of compliance to repository thermal and other limits. 
- Evaluations of cost trade-offs between the increased degree of separations and loss of value of fuel constituents (U, $\mathrm{Pu}, \mathrm{MA}$, hulls, etc.) if they are not recovered, and cost of decay storage.

- More holistic evaluations of SNF management options. Can the residual HLW streams from SNF separations be reduced through recycling and based on heat generation and radiotoxicity (rather than labeling based on the source of the waste), and can residual waste streams meet LLW class $\mathrm{A} / \mathrm{B} / \mathrm{C} /$ Greater Than Class $\mathrm{C}$ limits for potentially less costly and more available disposal?

- Consideration of other reprocessing costs besides costs of vitrification and disposal.

- Accounting for costs and impacts of radioactive waste generation from reprocessing facility operations and maintenance, and spent solvents/reagents, considering how reasonable or innovative variations in waste treatment and waste minimization can reduce those waste streams. 


\section{CONTENTS}

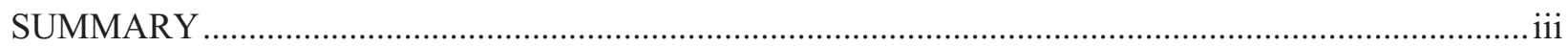

ACRONYMS

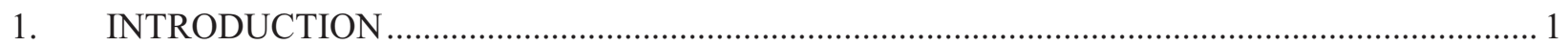

2. OBJECTIVE

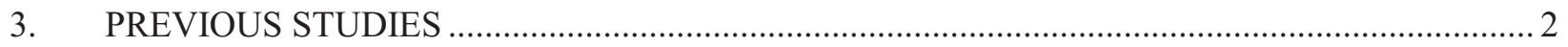

Integrated Waste Management Study …........................................................................ 2

3.2 Studies Conducted at Argonne National Laboratory …...................................................... 3

3.3 The Combined Waste Form Trade Study......................................................................... 4

3.4 The Management of Decay Heat from Spent Nuclear Fuel Study ........................................ 4

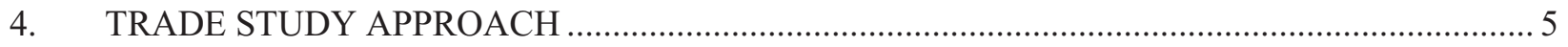

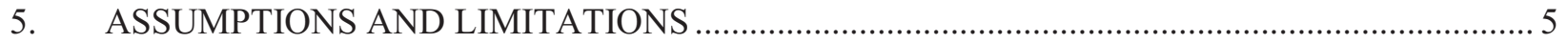

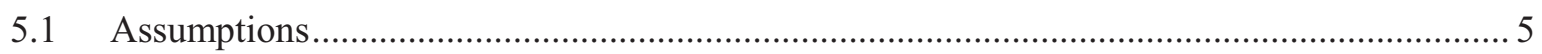

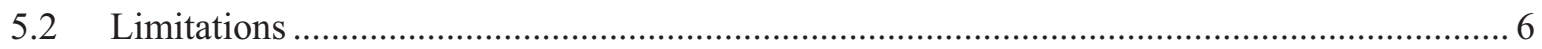

5.2.1 Limitations of Assuming HLW Disposal in the Yucca Mountain Repository............ 6

5.2.2 Limitations from the Glass Waste Form Assumptions ............................................ 7

5.2.3 Exclusion of Quantitative Radiotoxicity Evaluations .............................................. 7

6. SNF AGING AND SEPARATIONS TO INCREASE GLASS WASTE LOADING, REPOSITORY LOADING, AND LOWER HLW DISPOSAL COSTS …............................... 8

6.1 SNF Aging and Separations - Reduced Heat Generation and Increased Glass Waste

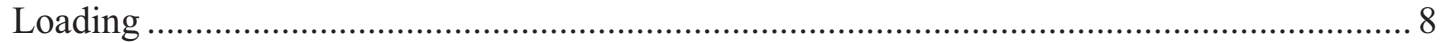

6.1.1 Net Fuel Value Less Vitrification and Disposal Costs............................................ 10

6.1.2 Reduction in Radiation Levels during SNF Aging ........................................... 12

6.2 SNF Aging and Separations - Reduced Radiotoxicity ................................................. 12

6.3 SNF Aging - Reduced Gaseous Fission Product Air Emissions .......................................... 14

7. REPOSITORY VENTILATION TO MEET TEMPERATURE LIMITS AND INCREASE

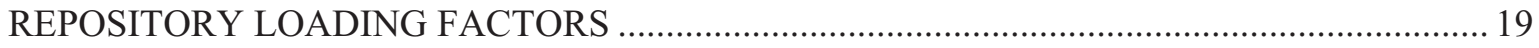

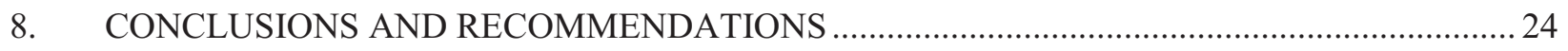

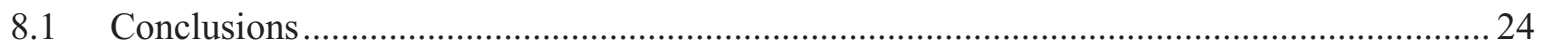

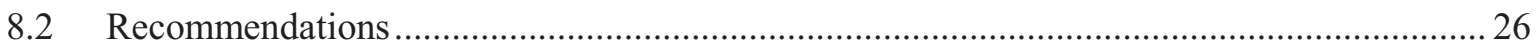

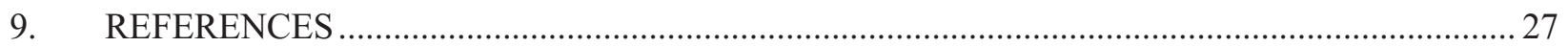




\section{FIGURES}

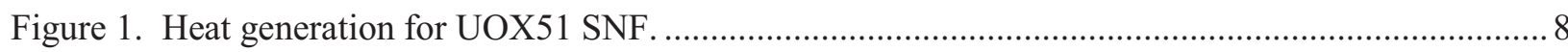

Figure 2. HLW treatment and disposal cost after aging SNF for selected actinide and UDS

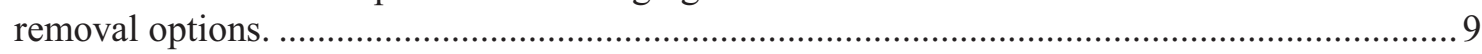

Figure 3. Fuel value of recovered fissile material value as recycled fuel. ............................................ 11

Figure 4. Net recycled fuel value less HLW vitrification and disposal costs for aging SNF prior to separations

Figure 5. SNF and separated HLW radiotoxicity relative to natural uranium (adapted from Piet 2009)... .13

Figure 6. Reduction in HLW radiotoxicity relative to direct-disposed SNF.

Figure 7. Estimated system removal factors needed to comply with air emissions regulations for spent fuel reprocessing facilities.

Figure 8. Hypothetical air dispersion model, resulting in this case in a calculated MEI distance from the stack of $800 \mathrm{~m}$ (Soelberg 2008).

Figure 9. SNF aging prior to reprocessing and the system removal factor for gaseous fission products.

Figure 10. Transient thermal response for reference direct disposal of PWR spent fuel (Case 1).

Figure 11. Transient thermal response for direct disposal of PWR spent fuel with $99.9 \%$ of Pu and Am removed, 150-year disposal delay, and 150-year ventilation (Case 36).

Figure 12. Transient thermal response for direct disposal of PWR spent fuel with $99.9 \%$ of Pu and Am removed. Same as Figure 11, but with minimum 50-year disposal delay and ventilation (Case 28).

Figure 13. Transient thermal response for direct disposal of PWR spent fuel with $99.9 \%$ of Pu and Am removed. Same as Figure 11, but with 100-year disposal delay and ventilation (Case 32).

\section{TABLES}

Table 1. Assumed partitioning of metals between dissolved and undissolved fractions in aqueous SNF separations. 10

Table 2. Radioactive gaseous fission products evolved to gas streams during SNF reprocessing. ........... 15

Table 3. Regulations governing radionuclide air emissions in the U.S. .............................................. 16

Table 4. Separations, disposal, and ventilation study; 50 GWD/MTIHM PWR spent fuel. 


\section{ACRONYMS}

ALARA as low as reasonably achievable

CCIM cold-crucible induction melter

DOE Department of Energy

Echem electrochemical

EPA Environmental Protection Agency

HLW high-level waste

IWMS Integrated Waste Management Strategy

LLW low-level waste

MA minor actinide

MEI Maximally Exposed Individual

MTIHM metric tons initial heavy metal

NESHAPS National Emission Standards for Hazardous Air Pollutants

NFBC nonfuel-bearing components

NRC Nuclear Regulatory Commission

NWPA Nuclear Waste Policy Act

PUREX plutonium-uranium extraction

PWR pressurized water reactor

SNF spent nuclear fuel

TMFP transition metal fission product

TSPA Total System Performance Assessment

UDS undissolved solid

UREX uranium extraction 
Heat Management Strategy Trade Study 


\section{HEAT MANAGEMENT STRATEGY TRADE STUDY}

\section{INTRODUCTION}

Thermal limits are imposed on radioactive waste geologic repository designs to protect materials stability and durability. These thermal limits can result in limits imposed on the amounts and placement of radioactive waste due to radioactive decay heat of that waste. Various spent nuclear fuel (SNF) separations processes now under consideration in the U.S. can separate some high-decay-heat radionuclides in the spent fuel for recycle or other disposal options, theoretically allowing for increased loadings of the remaining high-level waste (HLW) in the geological repository while still complying with the thermal limits.

Several studies have been performed in recent years to evaluate options for managing wastes generated from recycling SNF. These studies have included analyses of the potential compositions and properties of SNF, and the potential compositions, amounts, and properties of waste forms produced under various separations and recycling options. This Heat Management Trade Study has been performed in 2008-2009 to expand on these prior studies in continued efforts to analyze and evaluate options for cost-effectively managing SNF reprocessing wastes.

Until February 2009, SNF and HLW in the U.S. were destined for permanent geological disposal in the planned nuclear waste repository at Yucca Mountain in Nevada. Prior waste management studies were performed based on the assumption that Yucca Mountain would be the intended HLW disposal site. Plans for the Yucca Mountain repository have now been stopped pending the evaluation of other alternatives for handling SNF in the U.S.

Regardless of the geological repository architecture, thermal limits are expected to be imposed on geologic repository designs to mitigate consequences of heating the repository caused by decay heat generation from the emplaced HLW. Such consequences could result in thermal degradation or other changes in the structure of the rock formation or other natural and engineered barriers that could cause pathways for release of radionuclides to the environment and increased doses to human receptors sooner than or in excess of the repository design basis.

Different candidate geological repositories will likely have different thermal limits imposed based on their architectures and properties of the geological formations. The Yucca Mountain thermal limits, used in this study prior to February 2009, continue to be used because (a) these thermal limits have been developed during the Yucca Mountain design process, (b) there are no thermal limits for other potential repositories to base this study on, and (c) the results, based on the Yucca Mountain characteristics, are still (most likely) instructive and illustrative regardless of the eventual HLW repository situation.

Thermal limits based on the Yucca Mountain design are found in the Yucca Mountain Science and Engineering Report (U.S. DOE 2002). Two key temperature limits are of primary interest to this study. The first limit is a maximum temperature of $96^{\circ} \mathrm{C}$ for the mid-drift rock (the rock at the midpoint between parallel drifts, or tunnels). This temperature is the boiling point of water at the elevation of the disposal site. This limit ensures that water can always drain down through the rock between the emplacement drifts. The localized boiling front around a drift will limit water flow into the area around the waste, which is preferable to allowing a generalized boiling front around many drifts or the whole repository that could allow much greater pooling of groundwater above the waste. Pooling of water above the waste could eventually result in a greater risk of water entering the drifts and contacting the waste (eventually allowing transport of some waste materials), than if water, in smaller amounts, is allowed to normally flow between the drifts. 
The second temperature limit applies to the drift wall. The drift wall temperature is limited to less than $200^{\circ} \mathrm{C}$ to mitigate potential mineral phase transitions in the host rock that could increase risk of potential dose to a receptor due to changes in the local geology.

As defined in the Nuclear Waste Policy Act (NWPA) (U.S. DOE 2004), the capacity of the first geologic repository to be built in the United States will be limited to a total of 70,000 metric tons of heavy metal (MTHM) until a second repository is opened. The form will be either SNF in radioactive, used fuel assemblies from nuclear reactors, or HLW of various possible waste forms derived from reprocessing the SNF. Though this limit is purely legislative, strict regulatory and estimated technical limits also exist. The most important limit is for radiation dose, where the "Department of Energy (DOE) must demonstrate based on a performance assessment, that there is a reasonable expectation that, for 10,000 years following disposal, the reasonably maximally exposed individual receives no more than an annual dose of $0.15 \mathrm{mSv}$ (15 mrem) from releases from the undisturbed Yucca Mountain disposal system. DOE's analysis must include all potential pathways of radionuclide transport and exposure" (U.S. NRC 2005).

In addition to thermal limits for the repository, the waste form also has limits on the waste loading to ensure waste form durability. The borosilicate glass waste form assumed in this study has a maximum temperature limit assumed to be $500^{\circ} \mathrm{C}$, and limits on the concentrations of transition metal fission products (TMFP) and noble metals. Temperatures that exceed this limit could cause the glass to devitrify over time; concentrations of TMFP and noble metals could cause multiple phases in the glass. These conditions could cause reduced glass durability over time.

The repository loading efficiency of SNF or HLW from reprocessing SNF is limited by both the repository thermal limits and the waste loading limits for the waste form(s). This report contains results of evaluations of how to increase the loading efficiency and reduce disposal costs. The objective, approach, and several assumptions and limitations of the study are described in Sections 2, 4, and 5. Several previous, related studies are summarized in Section 3. Results of evaluations performed to increase the waste form loading (thereby increase repository loading, and reduce HLW disposal costs) through SNF aging and separations to remove U, Pu/Am, minor actinides (MA), and undissolved solids (UDS) from the assumed borosilicate glass waste from are provided in Section 6. Results of evaluations performed to increase repository loading by reducing short-term and long-term heat generation to meet repository thermal limits through SNF aging, separations, and repository ventilation are provided in Section 7. Conclusions and recommendations are summarized in Section 8.

\section{OBJECTIVE}

The primary objective of the Heat Management Trade Study was to evaluate strategies to most costeffectively increase the loading of waste in the repository without exceeding the temperature limits. Dose and volume limits are not specifically considered in this study, although dose is discussed qualitatively. This objective is based on the premise that either the legislated 70,000 MT limit in the NWPA could be increased or eliminated, such as could occur when a second repository becomes available.

\section{PREVIOUS STUDIES}

The Heat Management Trade Study builds on a foundation of several previous evaluations of waste management and heat impacts on repository disposal volumes.

\subsection{Integrated Waste Management Study}

The Global Nuclear Energy Partnership Integrated Waste Management Strategy (IWMS) was developed to manage and dispose of all wastes generated from advanced separations in SNF reprocessing, 
such as the uranium extraction (UREX) family of aqueous processes and the molten salt electrochemical (Echem) process (Gombert 2008a). The current version of the NWPA essentially envisions disposing of the waste from SNF reprocessing in a single waste form in a repository. A new generation of aqueous nuclear fuel reprocessing technologies, now in development under the auspices of the DOE Office of Nuclear Energy (NE), includes the capability to separate spent fuel into several fractions, thereby partitioning the wastes into groups of common chemistry. This technology advance enables development of waste management strategies that were not conceivable with plutonium-uranium extraction (PUREX) reprocessing. Conventional wisdom suggests that minimizing HLW volume and mass is desirable, but a logical extrapolation of this concept suggests that at some point the cost of further reducing HLW may reach a point of diminishing return and may cease to be cost-effective or even physically possible.

The IWMS was developed considering that a sustainable nuclear fuel cycle needs to manage SNF wastes in a safe manner at a large enough scale to be commercialized. The strategy evaluated the possible separated waste streams that contain waste constituents from the spent fuel $(\mathrm{Cs} / \mathrm{Sr}, \mathrm{Tc}$, undissolved solids, balance of fission products, lanthanides, etc.) on the basis of radioactive and chemical properties (halflife, chemistry relative to a waste form, decay heat generation, and radiotoxicity).

\subsection{Studies Conducted at Argonne National Laboratory}

Studies conducted at Argonne National Laboratory (Stillman 2004, Wigeland 2004, Wigeland 2006) evaluated the potential for increasing Yucca Mountain repository loading efficiency using advanced separations to recover specific radionuclides for special management and a nominal period of 75 years of active management with forced ventilation. Several conclusions were derived that are worth repeating:

- The mid-drift temperature constraint is primarily affected by the heat generation from long-lived actinides ( $\mathrm{Pu}$ and $\mathrm{Am})$, and the wall temperature constraint is primarily affected by short-lived fission products $(\mathrm{Cs} / \mathrm{Sr})$.

- Without reprocessing, the mid-drift temperature constraint limits the repository benefit (increased loading efficiency beyond the baseline loading efficiency) to $\sim 25 \%$ for combined aging of the fuel prior to placement in the repository and repository ventilation times for up to 150 years, because the long-term decay heat is dominated by plutonium $(\mathrm{Pu})$ and americium $(\mathrm{Am})$. Aging/ventilation for up to 150 years can dissipate heat from relatively short-lived radionuclides, but the heat generated after 150 years by the long-lived $\mathrm{Pu}$ and Am remains high enough to challenge the mid-drift temperature limit. Aging/ventilation for up to 150 years has a limited benefit to the repository, unless $\mathrm{Pu} / \mathrm{Am}$ are removed.

- Highly efficient (99.9\%) recovery of $\mathrm{Pu} / \mathrm{Am}$ for recycle could increase the repository loading efficiency by a factor of 4-6 and still maintain repository temperature limits within design constraints. SNF aging for only 5 years prior to aqueous processing is enough time for sufficient Am-241 ingrowth to require removal of both $\mathrm{Pu}$ and $\mathrm{Am}$.

- Once Pu/Am are removed, aging the waste for a total of $\sim 175$ years or highly efficient removal of the short-lived fission products could, theoretically, allow an increase in the repository benefit by a factor of $\sim 100$ (not considering other possible limits).

The studies recommend two points of caution on the results:

- The substantial repository efficiency gains are based on the assumption of $99.9 \%$ removal of target radionuclides. Even small losses (99\% recovery versus $99.9 \%$ ) in recovery (throughout the fuel cycle if the waste is disposed in the repository) can significantly reduce the projected benefits.

- The potential repository efficiency gains are projected without considering if waste forms are available that are suitable for repository disposal at the projected higher repository factors. 


\subsection{The Combined Waste Form Trade Study}

The Combined Waste Form Cost Trade Study (Gombert 2008b) builds on the IWMS by evaluating the potential decreases in HLW volumes produced from various SNF reprocessing schemes and the costs associated with that decreased HLW volume. With advanced separations being developed, it is now possible to match the waste form to the waste stream. Groups of elements from the spent fuel that are more environmentally stable as metals can be segregated from those that are more stable as oxides. Element groups can be separated and stabilized in forms to minimize the volume of HLW for disposal in the repository. Some separated streams (the spent hulls and other nonfuel-bearing components [NFBC]), gaseous fission products, and balance-of-plant wastes) were not included in this study.

The study showed that combining all of the waste streams that contain elements that are more stable as metals (the undissolved solids [UDS], Tc, and transition metal fission product [TMFP] streams) in a metallic form, and the oxides of $\mathrm{Cs}$, Sr, lanthanides ( $\mathrm{Ln}$ ), and other related elements in glass results in a minimum HLW volume; however, due to process capital and operating costs, this is not the most costeffective solution. The most cost effective solution (based on the assumptions of this study) is to combine all the UDS, Tc, and TMFP with the Cs/Sr/Ln oxides into a single glass HLW form. Sensitivity studies considering weight and heat, separations additives, waste loading, and HLW canister disposal costs indicate that this conclusion is robust over a wide range of these variables.

Thus, based on the assumptions of this study, producing separate glass and metal waste forms designed to reduce HLW disposal costs based on canister count cannot be justified based on cost. But other factors or metrics not included in this study may also affect the comparison of different waste form strategies. These factors/metrics include:

- Setting a greater premium on incremental HLW repository space, considering this uncertainty

- The fuel value of recycled $\mathrm{U}, \mathrm{Pu}$, and MA

- The potential and value of recycling some spent fuel materials such as cladding and other NFBC, and some other elements and isotopes (e.g., for medical, radiation, or heat uses)

- The potential to classify some separated waste forms as Class A/B/C or Greater-than-Class-C lowlevel waste (LLW), which may (eventually) have more available disposal options or lower disposal costs

- Changes in the number of radioactive material shipments of different types and distances

- The durability of metal, glass, or other waste forms tailored for the repository characteristics or for immobilizing short-lived, but high-heat/dose isotopes for shorter time periods, or for immobilizing long-lived isotopes for up to many thousands of years, until the radiotoxicity approaches safer levels.

\subsection{The Management of Decay Heat from Spent Nuclear Fuel Study}

The Management of Decay Heat from Spent Nuclear Fuel study (Jones 2008) was initiated to examine various scenarios to reduce the decay heat of SNF or HLW at emplacement, thereby increasing the potential capacity of the repository. SNF contains radionuclides that generate heat as they decay. The greatest heat-generating radionuclides in spent fuel are the actinides $\mathrm{Pu}, \mathrm{Am}, \mathrm{Cm}$ and the fission products Cs and Sr. This decay heat of the SNF or of the HLW generated by reprocessing will constrain the amount of material that can be disposed based on temperature limits in the repository (assumed at the time to be Yucca Mountain). Other potential limits to the repository capacity, such as radiotoxicity limits or limits on waste form loadings, are not considered in this study.

The scenarios analyzed included decay storage of SNF followed by direct disposal, as well as several reprocessing schemes combining separation and decay storage. The analysis indicated that the repository 
loading could be increased by 4-6 times compared to direct SNF disposal by removing Pu and Am for recycle. If $\mathrm{Cs}$ and $\mathrm{Sr}$ are also removed and managed separately (either by disposal elsewhere, decay storage followed by repository disposal, etc.), then the repository loading could be increased by a total of up to about 40 times. If $\mathrm{Cm}$ is also removed, then the repository loading could be increased by a total of about 200 times. Because these increases were only based upon heat generation and no account was taken for other possible limits, the viability of the waste form, how the increase could be physically implemented, or the economics of a given option, it is unlikely that such large increases can be realized.

\section{TRADE STUDY APPROACH}

Studies referenced above have shown that based on the current design of the Yucca Mountain repository, little can be gained in terms of disposal efficiency by aging fuel or extending ventilation, without at least some SNF separations and recycle, to meet the mid-drift temperature constraint. SNF reprocessing to recover at least $\mathrm{Pu} / \mathrm{Am}$ is necessary to attain substantial benefits with respect to meeting the mid-drift temperature constraint. While there is some debate about the conservatism built into the Yucca Mountain design, it has been the reference system for SNF/HLW disposal in the United States.

The relative repository loading factors and costs of several variations were evaluated in this trade study. Parameters that were varied include:

- Age of the SNF prior to reprocessing and prior to emplacement in the repository

- Uranium, plutonium, and minor actinide (MA) separation from the SNF for recycle, and separation efficiencies

- Fuel value of the recycled Pu and MA

- Length of time that active ventilation is employed in the repository.

Relative differences in cost were estimated by assuming constant per-canister vitrification and disposal costs, and varying the number of canisters according to calculated waste loadings needed to meet glass heat generation and concentration limits determined for different SNF aging and separations options. The fuel value of separated fissile material was also considered. The cost impacts were used to evaluate reprocessing and waste management strategies to maximize repository benefit versus cost.

\section{ASSUMPTIONS AND LIMITATIONS}

This trade study is based on several assumptions about SNF, separations processes, and repository requirements. The results of the trade study have some limitations that should be considered when using the results. Defining assumptions and limitations is critical to ensuring understanding of the results of an analysis and to allow future studies to build on the results without inadvertently misapplying them.

\subsection{Assumptions}

Assumptions for this study include:

- SNF source term. Unless otherwise indicated for a particulate analysis done by other studies, the assumed initial uranium enrichment of the fuel is $4.4 \%$, and the assumed burnup is 51 giga-watt days per metric ton initial heavy metal (GWD/MTIHM). The composition of the SNF was based on Origen calculations. This SNF source term is the same source term or similar to the source term used in prior waste management studies cited in Section 3.

- SNF source term for Section 7 on repository ventilation. The assumed pressurized water reactor (PWR) spent fuel burnup is 50 GWD/MTIHM. 
- Repository temperature limits. The design basis used to establish temperature limits and thus SNF/HLW disposal limits was based on Yucca Mountain. The temperature limits were based on a design of linear drifts with waste canisters disposed on tracks in the drifts. These temperature limits include:

- $\quad 350^{\circ} \mathrm{C}$ maximum SNF cladding temperature

- $\quad 300^{\circ} \mathrm{C}$ maximum waste package surface temperature

- $\quad 200^{\circ} \mathrm{C}$ drift wall temperature

- $\quad 96^{\circ} \mathrm{C}$ mid-drift temperature.

- HLW characteristics. A single borosilicate glass waste form was selected for simplicity in this analysis rather than considering a suite of waste forms for each of the separation processes. The use of a glass waste form results in limits imposed on the composition and waste loading to ensure that the glass is durable for long time periods. The highest possible waste loading for acceptable glass durability is the lowest waste loading calculated based on heat generation and waste constituent solubility in the glass to ensure that the glass contains only a single major vitrified phase and does not devitrify over time.

- The glass waste loading is limited to the value which results in a glass canister center temperature of $500^{\circ} \mathrm{C}$ or less. This temperature limit is assumed to be sufficient and necessary to avoid glass devitrification over time, which it if occurred, could cause the glass to become less durable.

- Glass canister heat transfer modeling using the assumed $500^{\circ} \mathrm{C}$ centerline temperature limit results in a maximum heat generation rate of about $14,000 \mathrm{~W}$ for glass canisters that are 2 feet diameter and 15 feet long and hold $1.33 \mathrm{~m}^{3}$ glass with a density of $2,700 \mathrm{~kg} / \mathrm{m}^{3}$ (Dixon 2009). This limits the waste loading in the glass, depending on the concentrations of heat-generating isotopes in the waste, to levels that limit the maximum heat generation to $14,000 \mathrm{~W}$.

- Glass durability is also assumed to be satisfactory as long as no significant separate phases exist in the glass. Waste constituent concentrations must be less than their respective solubility limits in borosilicate glass. The maximum concentration limit for $\mathrm{MoO}_{3}$ is assumed to be $2 \mathrm{wt} \%$. The maximum concentration limit for noble metal oxides $\left(\mathrm{RuO}_{2}, \mathrm{Rh}_{2} \mathrm{O}_{3}\right.$, $\left.+\mathrm{PdO}\right)$ is assumed to be $3 \mathrm{wt} \%$.

- Cost assumptions. The combined transportation, temporary storage, and disposal cost is assumed to be $\$ 850,000$ per glass canister, regardless of canister size. The vitrification process cost is assumed to be $\$ 176,000$ per canister for 2 feet $\times 15$ feet glass canisters, derived in an analysis from the Minor Actinide Study (Carter 2009). Other costs such as for temporary SNF storage and for SNF separations were not included in the scope of this study.

\subsection{Limitations}

Just as critical to defining the assumptions behind a study is to understand the explicit and implicit limitations caused by using those assumptions. Sensitivity studies can be used to help determine if the assumptions are as limiting as they first appear, but it must be understood that the initial assumptions define ranges of the ultimate results. Poor selection of assumptions can render the best study essentially useless, but some limitations are unavoidable, similar to the error propagation in all calculations using estimates and imprecise measurements. Recognized limitations in this study are described in the following subsections.

\subsubsection{Limitations of Assuming HLW Disposal in the Yucca Mountain Repository}

The Total System Performance Assessment (TSPA) is based on a number of assumptions relative to Yucca Mountain geology and climate, repository design, SNF and HLW types and relative amounts, as well as a tremendous amount of experimental data to characterize the durability of the disposed materials. 
The results of the study and how it applies to other repository environments and disposal inventories can thus only indicate trends. A more quantitative result, which relies on more precise quantification of potential radionuclides release, would require modeling, similar to the TSPA, for an inventory derived from large-scale reprocessing resulting in mostly HLW with only a limited amount of SNF in a particular environment.

This study also uses results from heat-transfer models developed to represent the Yucca Mountain design and geology, including certain temperature constraints chosen to limit the risk associated with radionuclide fate and transport through the subsurface environment. It is believed that similar temperature limits will impose heat generation limits on any geologic repository yielding similar trends to those described in this report, but, without developing models specific to a known geology, extrapolating the results of this study to other sites cannot be quantified.

\subsubsection{Limitations from the Glass Waste Form Assumptions}

This study is limited to an evaluation of heat management and does not consider the relative merits of different waste forms such as SNF assemblies, glass, and other waste forms. While the relative durability of any of these materials may impact the release rate and/or the fate and transport modeling results from a future TSPA analysis, fuel and glass are used as representatives of a family of potential stabilized forms for radionuclides.

Waste loading and the derivative canister capacity is limited based on glass processing and stability limits, as defined above. Devitrification of glass may be acceptable with more characterization work, which would allow higher centerline temperatures and increased waste loading.

Similarly, alternate waste forms or the use of a different melter technology, such as the cold-crucible induction melter (CCIM), may allow higher concentrations of noble metal oxides and $\mathrm{MoO}_{3}$, which could enable higher waste loadings that could impact the results of this study.

Stabilizing an isotope like technetium in a metallic form for a reducing environment, or iodine in a salt form for a repository in a salt deposit, both of which may be possible for aqueous processing or necessary for electrochemical processing, may have desirable durability benefits relative to glass, similar to matching any waste form to the chemistry of a particular radioisotope and a repository environment. Evaluating potential increased durabilities of such waste forms, and potential improved immobilization of waste forms tailored for disposal in specific repository designs is outside the scope of this study.

\subsubsection{Exclusion of Quantitative Radiotoxicity Evaluations}

Radiotoxicity is a theoretical metric for quantifying the toxicity of an inventory of radioactive material, unmitigated by physical or chemical limits, including solubility, natural limits on subsurface migration, or any natural or engineered barriers in the overall pathway to a receptor. In principle, the lower the radiotoxicity, the less risk of potential dose due to an unforeseen failure in barriers designed to prevent dose. However, this can also be extrapolated inappropriately and result in some misleading conclusions. While the concept of radiotoxicity is useful to compare between two inventories, and any reduction in magnitude or lifetime is good, it may not be warranted without careful examination using a model such as the TSPA. The results must then be evaluated in a trade-study that objectively considers reduction in risk of potential dose versus cost, similar to any as low as reasonably achievable (ALARA) analysis for chemical or radioactive materials. In this study, heat management is the focus, and radiotoxicity is considered only qualitatively. 


\section{SNF AGING AND SEPARATIONS TO INCREASE GLASS WASTE LOADING, REPOSITORY LOADING, AND LOWER HLW DISPOSAL COSTS}

Repository loading can be increased, and HLW disposal costs can be decreased, by allowing radioactive isotopes in SNF assemblies to decay while in wet or dry storage after removal from the reactor but prior to reprocessing. In this analysis, different aging times and different $U$ and actinide separations options were assumed in calculations of the numbers of glass waste canisters that result from different waste loadings allowed to ensure that the glass centerline temperature does not exceed $500^{\circ} \mathrm{C}$, and concentration limits for TMFP and noble metals are not exceeded. A single borosilicate glass waste form was assumed for the HLW remaining after separating $U$ and actinides for recycle. Vitrification and disposal costs were estimated based on the number of canisters for the different options.

\subsection{SNF Aging and Separations - Reduced Heat Generation and Increased Glass Waste Loading}

Aging the SNF prior to reprocessing lowers the amounts of the shorter-half-lived isotopes, which lowers the short-term heat generation and the radioactivity. Figure 1 shows that the higher-heat groups of elements for the first 100 years are Group 1A and IIA (Cs/Sr) and actinides. The Cs/Sr, Ln, and TMFP product groups have higher heat generation than do the actinides $(\mathrm{Pu}+$ progeny and $\mathrm{MA}+$ progeny) for about the first 5 years, but the relatively fast decay of some of the Ln and TMFP elements results in heat generation lower than the actinides for both of these groups after about 5 years. For SNF aged more than 5 years, the heat generation from the actinides (over the long term, greater than about 100 years) and from $\mathrm{CsSr}$ (over the short term up to 100 years) dominate the total heat generation. This is why combining either SNF aging (or CsSr removal) and actinide removal provide the greatest benefit for reducing both the short and long-term heat generation.

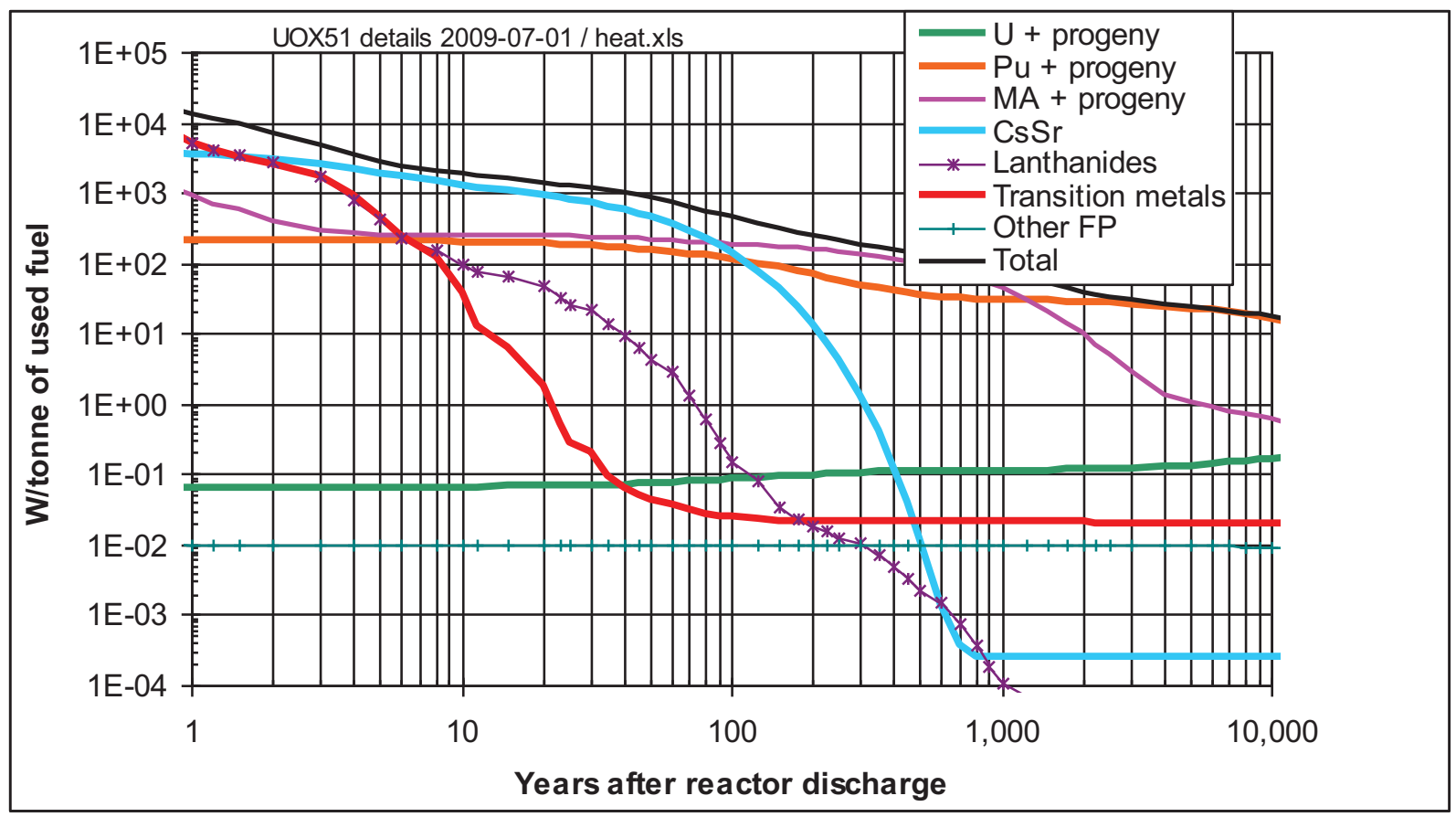

Figure 1. Heat generation for UOX51 SNF. 
The reduced heat generation after SNF aging enables higher waste loadings for separations options where the glass waste loading is limited by heat generation in the glass. Increasing the glass waste loading decreases the total amount of glass per unit of SNF processed, resulting in fewer glass canisters for disposal. All else being constant, the total vitrification and disposal costs decrease when the number of canisters decreases.

Figure 2 shows how the treatment and disposal cost is affected for different SNF aging and separations options. These costs were estimated by calculating the number of 2 feet $\times 15$ feet glass canisters that would be required for different glass waste loadings that would occur for the different SNF aging and separations cases that were considered. The maximum glass waste loading for each case was the lowest waste loading value determined based on the canister heat generation and the glass centerline temperature limit, or the based on the concentration of $\mathrm{MoO}_{3}$ and noble metals compared to their concentration limits. A reprocessing facility operating at $800 \mathrm{MTIHM} /$ year was the assumed basis, and the cost was based on an assumed cost of $\$ 85,000 /$ canister for handling and disposal.

Removing only the U for recycle from the SNF still leaves the element groups with relatively high short-term heat elements, the transition metals, and noble metals in the waste that is vitrified. Aging the SNF prior to processing (or after separations) for about 20 years lowers the number of glass canisters and the treatment and disposal cost by about $\$ 80$ million/year (about 50\%) compared to processing after 5 years aging. The corresponding repository loading factor would be about 2. Aging the SNF beyond 20 years provides no additional cost or volume benefit, because the waste loading and resulting volume of the HLW glass is limited by the amount of TMFP (in particular, $\mathrm{MoO}_{3}$ ) in the glass. This figure also shows:

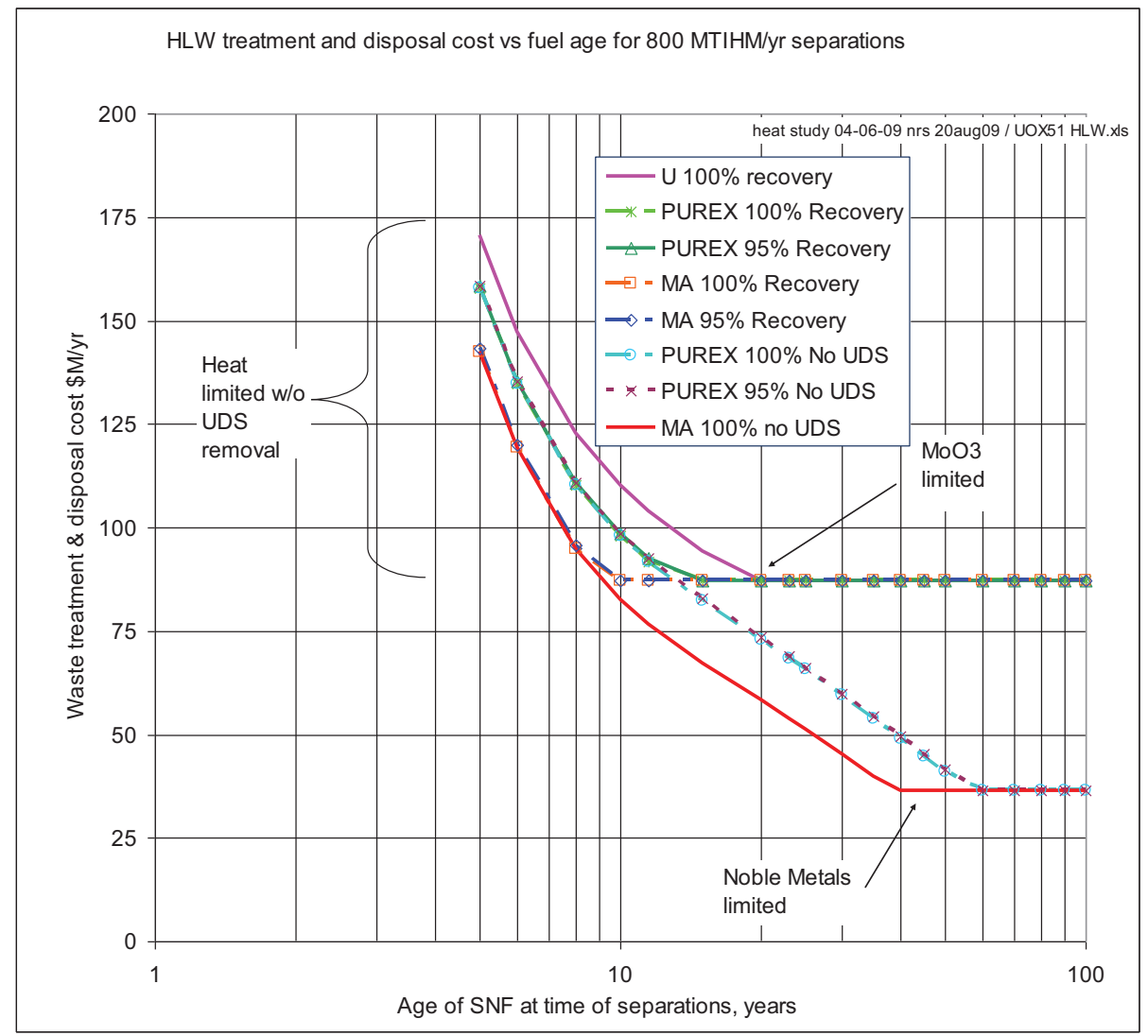

Figure 2. HLW treatment and disposal cost after aging SNF for selected actinide and UDS removal options. 
- Removing $95 \%$ or $100 \%$ of the Pu along with $100 \%$ of the $\mathrm{U}$ shortens the beneficial aging time to about 15 years, at which time the concentration of the TMFP becomes the limiting factor. Removing $100 \%$ of the Pu provides no appreciable benefit compared to removing only $95 \%$ of the $\mathrm{Pu}$.

- Removing $95 \%$ or $100 \%$ of the MA along with $100 \%$ of the U and Pu shortens the beneficial aging time to about 10 years, at which time the concentration of the TMFP becomes the limiting factor. Removing $100 \%$ of the MA provides no appreciable benefit compared to removing only $95 \%$ of the MA.

- Removing $100 \%$ of the UDS (which contains most of the TMFP according to partitioning assumptions shown in Table 1) lowers the waste loading limit based on the TMFP. Elemental partitioning between dissolved material and the UDS is not currently resolved for different separations scenarios. Variations in these partitioning assumptions could change the results of this analysis. Then, SNF aging to reduce heat generation for up to 40-60 years provides additional vitrification and disposal cost savings until the waste loading limit imposed by remaining noble metals in the glass is reached. The maximum cost savings from aging could be over $\$ 100$ million/year (about 70\%). The corresponding repository loading factor would be about 3 .

Table 1. Assumed partitioning of metals between dissolved and undissolved fractions in aqueous SNF separations.

\begin{tabular}{|c|c|c|}
\hline Element & Soluble & $\begin{array}{c}\text { Insoluble } \\
\text { (bound in UDS) }\end{array}$ \\
\hline $\mathrm{Mo}$ & $7 \%$ & $93 \%$ \\
\hline $\mathrm{Ru}$ & $53 \%$ & $47 \%$ \\
\hline $\mathrm{Rh}$ & $61 \%$ & $39 \%$ \\
\hline $\mathrm{Pd}$ & $71 \%$ & $29 \%$ \\
\hline
\end{tabular}

The cost of vitrifying HLW was estimated to be $\$ 176,000 /$ canister, averaged from ranges of capital and operating costs, and estimated ranges in numbers of glass canisters produced, reported in Carter 2009.

\subsubsection{Net Fuel Value Less Vitrification and Disposal Costs}

When the separation of $\mathrm{U}, \mathrm{Pu}$, and MA from SNF for recycle is delayed more than 4 years, then some of the fuel value of the recycled material is lost due to decay, as shown in Figure 3 (the fuel value of the TRU and U/TRU actually increases slightly for the first 4 years). The values in this figure were estimated by calculating the value of new $4.1 \%$ enriched uranium fuel for a thermal reactor that can be replaced by the corresponding amount of recycled $\mathrm{Pu}$ and U/TRU, using estimates for new uranium mining, conversion, and enrichment from the Boston Consulting Group. The fuel value assuming a fast reactor fuel would be about 3 times higher, so this estimated fuel value is conservative. Losses in value of TRU and U/TRU are small, under $1-2 \%$ total, for fuels aged to 125 years before reprocessing. However, the fuel value of the $\mathrm{Pu}$ decreases by about $0.5 \%$ per year for the first 10 years of aging; by about $0.4 \%$ per year for the next 10 years; by about $0.3 \%$ per year for the next 10 years; by about $0.2 \%$ for the next 10 years; and by about $0.1 \%$ for the next 20 years. 


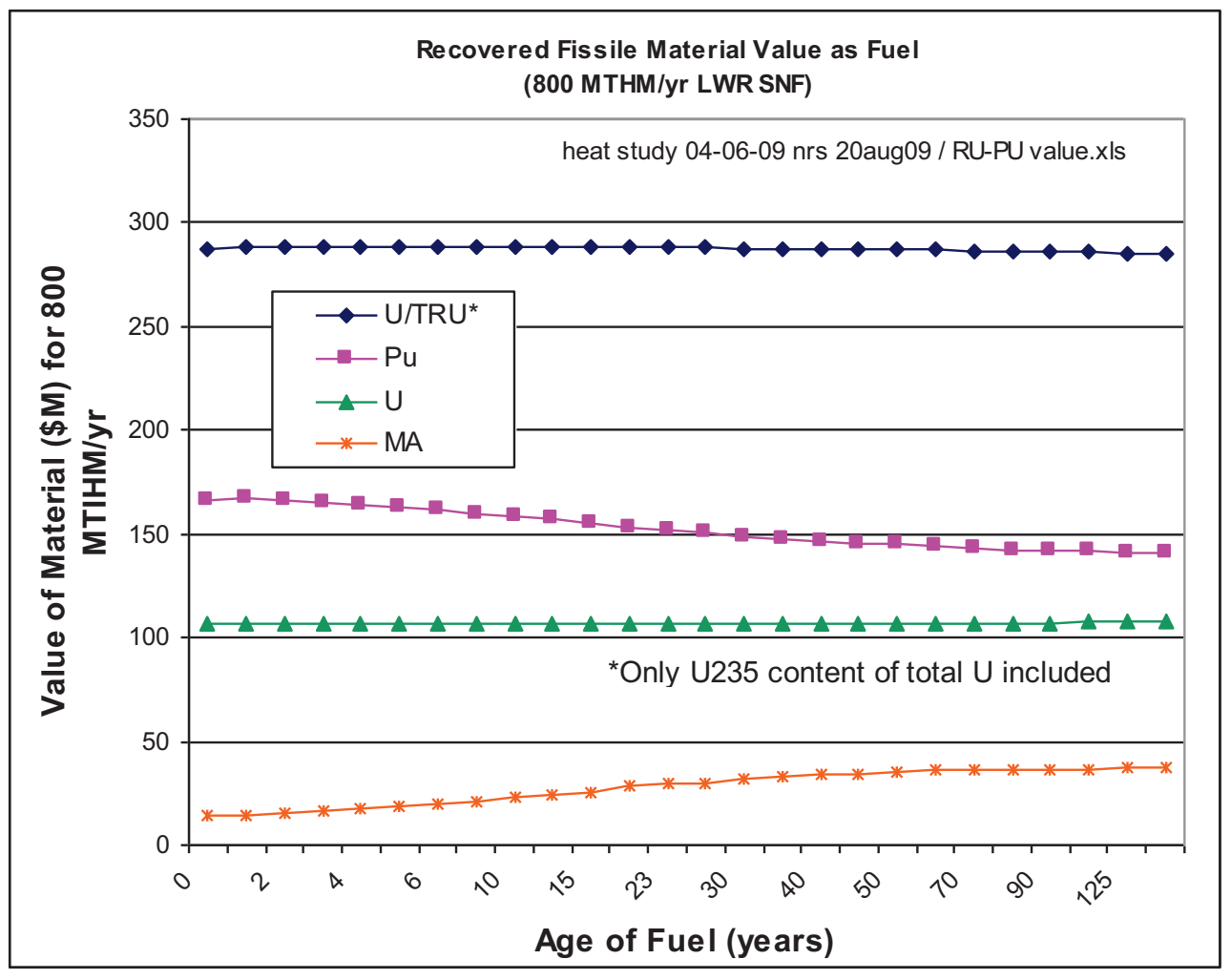

Figure 3. Fuel value of recovered fissile material value as recycled fuel.

The recycled $\mathrm{Pu}$ fuel value is included with the vitrification and disposal cost savings in Figure 4. Other cost factors such as temporary storage and separations costs were not included in the scope of this analysis, and this analysis is not intended to represent total estimated costs for the lifecycle of SNF. This figure shows:

- For SNF aged at least 5 years, a net value results from considering the fuel value of the recycled materials after subtracting the vitrification and disposal costs for the remaining HLW (for all cases except for the $\mathrm{U}$ recovery only case, with less than about 10 years of SNF aging)

- The net value increases as the SNF ages, until the respective $\mathrm{MoO}_{3}$ and noble metals concentration limits in the glass are reached. After these glass limits are reached, then further SNF aging results in slight decreases in the net value. The largest decrease occurs for the two PUREX cases (UDS still included), where the net value decreases slightly if the SNF ages beyond about 11 years, because of the loss of $\mathrm{Pu}$ without recovering any of the MA value (that contains increasing value from the ingrowth of Am-241).

- The net value increases with increasing completeness of recycle (recovering Pu provides much more value than recovering $\mathrm{U}$ only, and recovering $\mathrm{U}, \mathrm{Pu}$, and $\mathrm{MA}$ for recycle, and removing the UDS, provides the greatest value). 


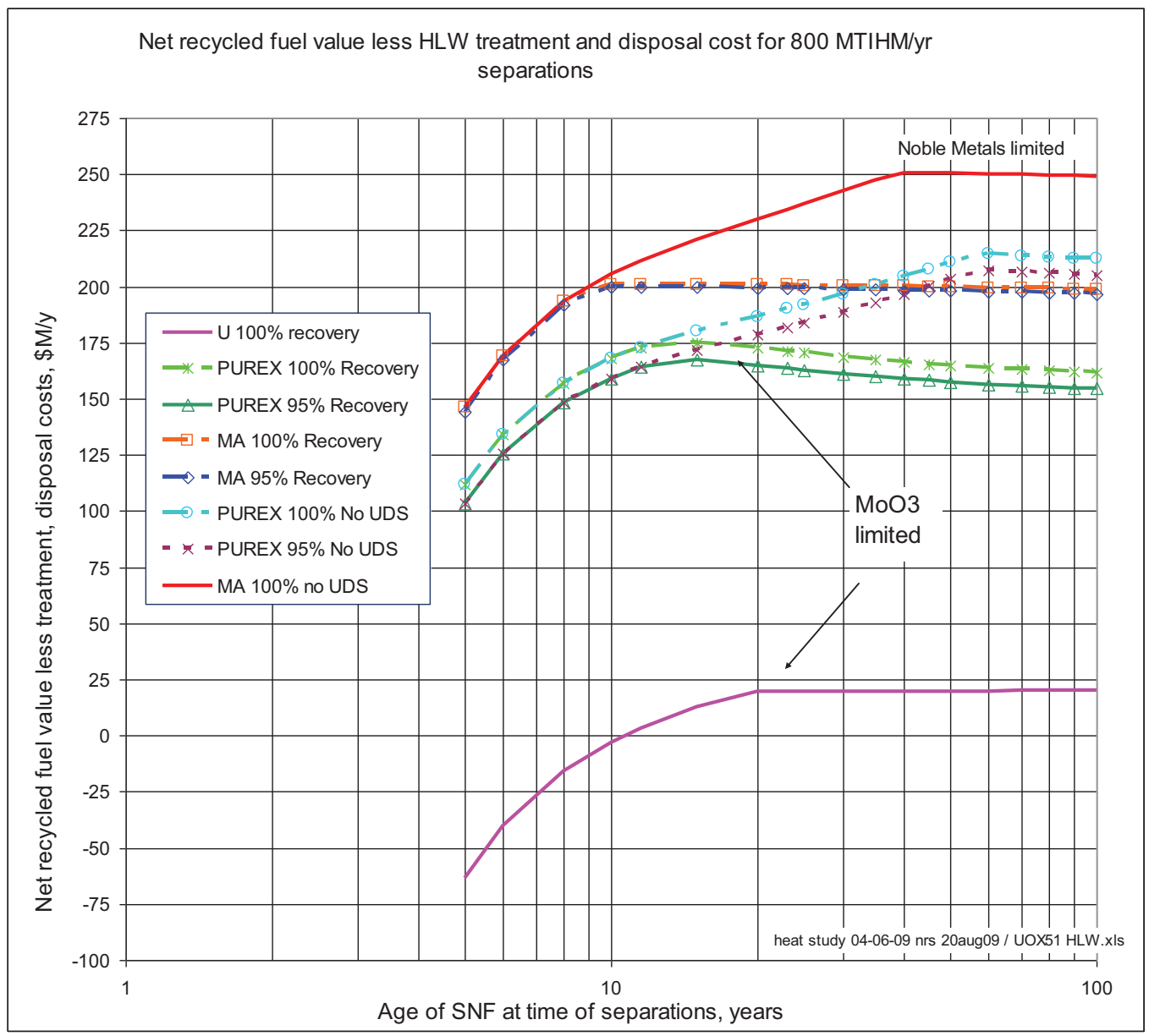

Figure 4. Net recycled fuel value less HLW vitrification and disposal costs for aging SNF prior to separations.

\subsubsection{Reduction in Radiation Levels during SNF Aging}

In addition to decreasing the number of canisters to be disposed, thereby reducing the cost for treatment and disposal, aging SNF prior to reprocessing lowers the radiation levels of the SNF. Aged SNF has lower radioactivity than greener SNF. This lowers the amount of shielding needed for temporary storage, transport, and processing facilities, lowers the dose hazard to personnel, and lowers the amount of damaging radiation to which the equipment is exposed. The lower radiation levels may result in handling, storage, processing, and transportation cost savings that are not included in this study.

\subsection{SNF Aging and Separations - Reduced Radiotoxicity}

Aging SNF prior to reprocessing, delaying repository emplacement of separated HLW after reprocessing, and recovering some groups of radionuclides from SNF during reprocessing, all can lower the remaining radiotoxicity of the waste when emplaced in a repository. Current calculations set the dose risk from direct disposal of SNF in the Yucca Mountain repository at $0.24 \mathrm{mrem} / \mathrm{year}$, which is about 60 times lower than the allowable Yucca Mountain limit of $15 \mathrm{mrem} / \mathrm{year}$. Thus, the dose risk is not the limiting factor for the amount of direct-disposed SNF that was regulatorily allowed to be disposed in Yucca Mountain. Holding all other factors that can affect the dose risk constant, SNF aging or separations processes can theoretically achieve a 60 times more repository benefit factor before reaching 
the dose risk limit. However, as Figure 5 shows, SNF aging and separations both remove some of the radiotoxicity in the remaining waste by removing some of those elements that contribute to the radiotoxicity (Piet 2009). Aging the direct-disposed (5-year cooled) SNF 100 years, for example, reduces the radiotoxicity of that SNF by about 4 times.

Aging SNF prior to reprocessing and recovering some groups of radionuclides from SNF during reprocessing can also shorten the time during which waste in the repository exhibits radiotoxicity greater than that of uranium. As indicated in Figure 5, direct-disposed SNF can exhibit radiotoxicity greater than natural uranium for over 400,000 years. Aging SNF for 100 years prior to emplacement in the repository has a negligible 100 -year reduction in that 400,000 year time period.

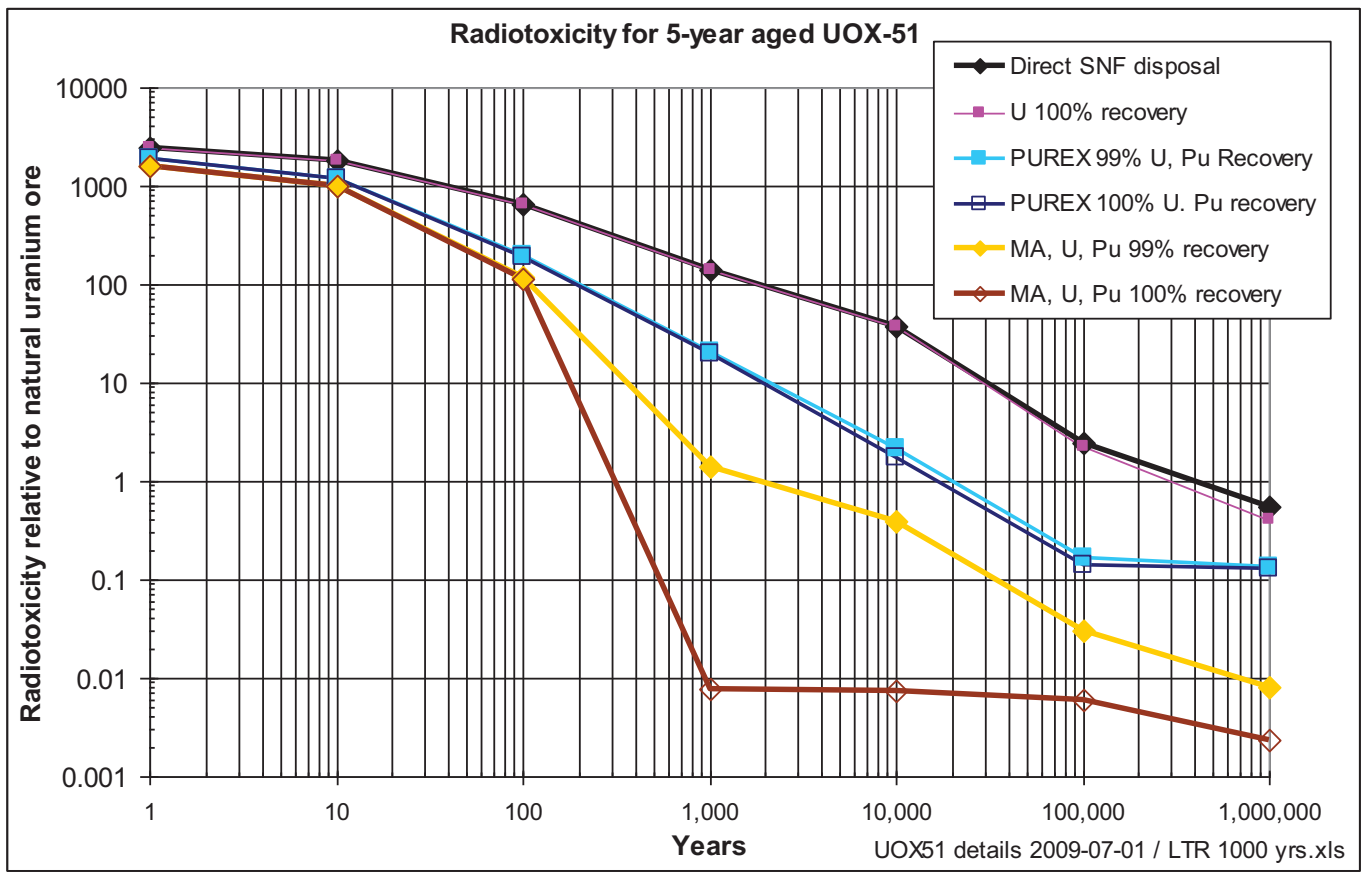

Figure 5. SNF and separated HLW radiotoxicity relative to natural uranium (adapted from Piet 2009).

Figure 5 also shows that significant reductions in the time during which HLW is more radiotoxic than natural uranium occur are achievable for different separations scenarios. Recovering $100 \%$ of the uranium decreases the duration during which the radiotoxicity of the remaining waste exceeds that of natural uranium to about 300,000 years. The recovery of at least $99 \%$ of the $\mathrm{U}$ and $\mathrm{Pu}$ reduces that time period to less than 20,000 years. Recovery of at least $99 \%$ of $\mathrm{U}, \mathrm{Pu}$, and MA reduces this time period to under 2,000 years, and removal of $100 \%$ of the $\mathrm{U}, \mathrm{Pu}$, and MA reduces this time period to about 300 years. So, depending on the $\mathrm{U}, \mathrm{Pu}$, and MA removal efficiency that is actually achievable (as long as it is at least 99\%), the time during which the remaining waste is more toxic than natural uranium can range between about 300 and 2,000 years. While regulations for radioactive waste disposal are not based on the radiotoxicity of natural uranium, this analysis shows that if the $\mathrm{U}, \mathrm{Pu}$, and $\mathrm{MA}$ are efficiently recycled, the time duration when the remaining waste exhibits elevated radiotoxicity is short enough that other ways (waste forms and packaging) to immobilize the waste might be sufficient so that the waste may not require deep geological disposal to limit the dose risk to acceptable levels. 
Figure 6 shows how the radiotoxicity of waste remaining after separations can be reduced compared to direct-disposed SNF. Removing U does not significantly reduce the radiotoxicity of the spent fuel for 100,000 years, because the radiotoxicity from $U$ is actually due primarily to decay products radium and radon which takes time to build in. Removing the Pu reduces the radiotoxicity by 1.3 to 21 times, depending on age.

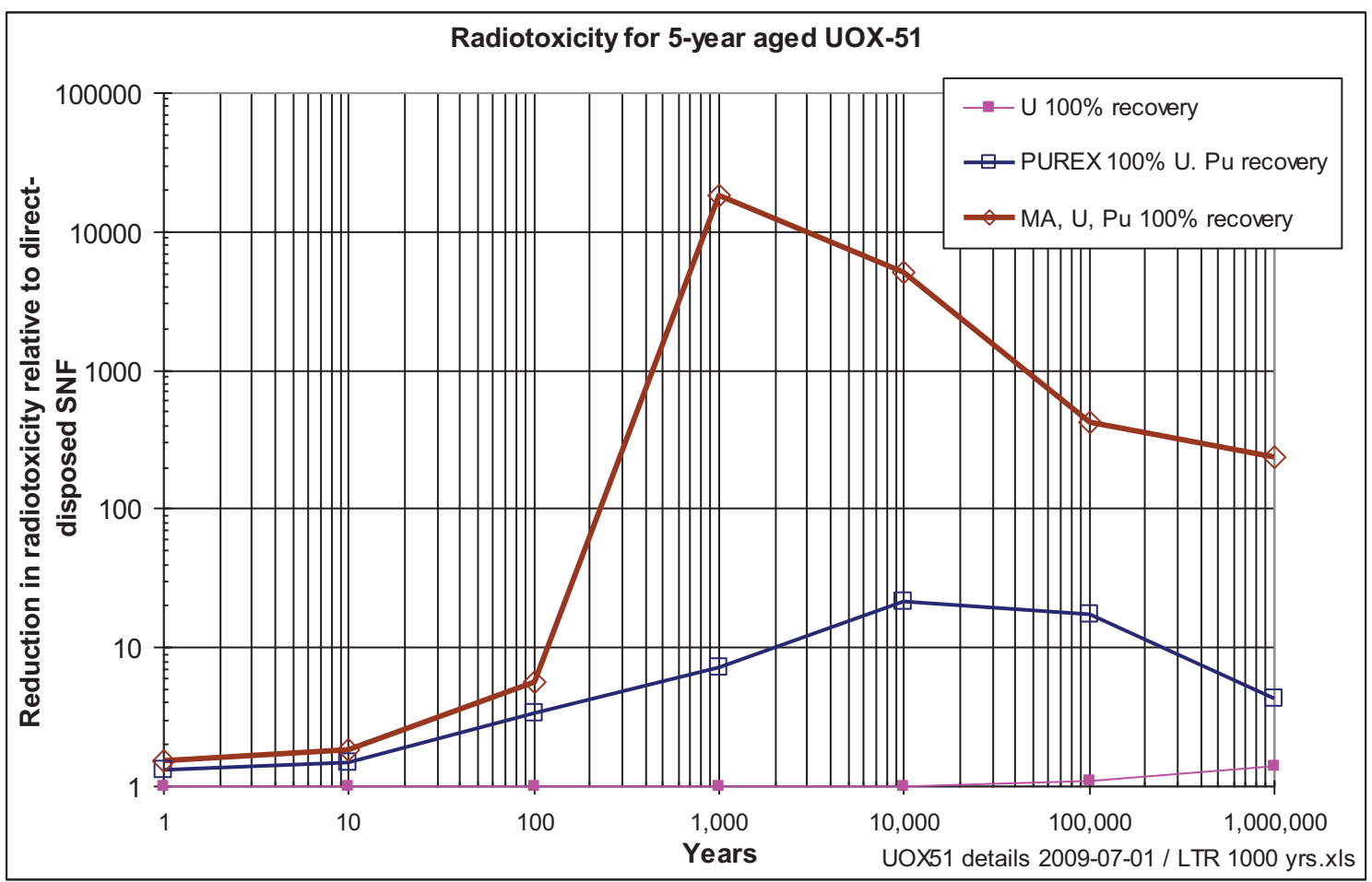

Figure 6. Reduction in HLW radiotoxicity relative to direct-disposed SNF.

Removing the MA also does not significantly reduce the dose risk in the first 10 years, but after 100 years the dose risk is reduced by almost 10 times or more, and the long-term dose risk (after 1,000 years) is reduced by between 2 to 4 orders of magnitude.

The greatest reduction in dose risk is achieved by removal of $\mathrm{U}, \mathrm{Pu}$, and MA (which achieves only about a 1.5-time reduction after 10 years, but 2 to 4 orders of magnitude reduction after 100 years).

\subsection{SNF Aging - Reduced Gaseous Fission Product Air Emissions}

Spent nuclear fuel contains several radioactive fission products that tend to evolve into gaseous streams during spent fuel reprocessing. Heat management analyses that consider aging the SNF prior to reprocessing include the added benefit of providing time that allows decay of shorter-lived gaseous radionuclides prior to when those radionuclides would be released from the SNF during reprocessing.

Gaseous radionuclides with concentrations high enough and with half lives long enough to be a concern during spent fuel reprocessing and disposal are shown in Table 2. This table also shows estimated percentages of these gaseous fission products that are typically released from the SNF during reprocessing. If these radionuclides were to decay enough prior to SNF reprocessing, then the current integrated waste management strategy that assumes that all these radionuclides may require capture and disposition in waste forms could be simplified. 
Table 2. Radioactive gaseous fission products evolved to gas streams during SNF reprocessing.

\begin{tabular}{|c|c|c|c|}
\hline \multirow[b]{2}{*}{ Gaseous fission product } & \multirow[b]{2}{*}{$\begin{array}{c}\text { Half life, } \\
\text { years }\end{array}$} & \multicolumn{2}{|c|}{ Percentage evolved to gas streams during reprocessing } \\
\hline & & $\begin{array}{l}\text { Aqueous separations } \\
\text { and waste treatment }\end{array}$ & $\begin{array}{l}\text { Echem separations and } \\
\text { waste treatment }\end{array}$ \\
\hline $\mathrm{Kr}-85$ evolves as a noble gas & 10.7 & 100 & 100 \\
\hline $\begin{array}{l}\text { Tritium }(\mathrm{H}-3) \text { evolves in } \\
\text { tritiated water, } \mathrm{H}_{2} \text {, or in other } \\
\text { gaseous species }\end{array}$ & 12.4 & 100 & 100 \\
\hline $\begin{array}{l}\mathrm{C}-14 \text { evolves in } \mathrm{CO}, \mathrm{CO}_{2} \text {, or } \\
\text { hydrocarbon compounds }\end{array}$ & 5,740 & 100 & 10 \\
\hline $\begin{array}{l}\text { I-129 evolves in HI, organic } \\
\text { iodine compounds, or } \mathrm{I}_{2}\end{array}$ & $1.57 \mathrm{E}+7$ & 100 & 10 \\
\hline
\end{tabular}

Notes:

1. Aqueous separations processes being studied in the U.S. typically include processes to produce only solid product and waste forms. These processes tend to eventually evaporate or otherwise thermally treat all produce and waste streams, driving these species into off-gas streams. Off-gas control systems are included to capture these gas species with the efficiencies needed to meet air emission limits.

2. Electrochemical separations processes use molten salt baths to electrochemically separate spent fuel constituents. These molten salt baths have little absorptive affinity for noble gas and $\mathrm{H}$ species, so $\mathrm{Kr}-85$ and $\mathrm{H}-3$ species are assumed to evolve into off-gas streams. The molten salt baths have affinity to absorb both halides and carbon/carbonate compounds. Realistic separation factors for C-14 and I-129 species are not well known. For the purposes of this study, 90\% of the C14 and I-129 are assumed to be retained in the molten salt that eventually becomes incorporated into a solid waste form for disposal.

Various regulations, shown in Table 3, apply in the U.S. for air emissions of radionuclides emissions. Some of these regulations depend on whether the source facility is owned or operated by the U.S. DOE or is a Nuclear Regulatory Commission (NRC) licensee (such as a commercial SNF reprocessing facility would be).

The degree of control of air emissions of gaseous radionuclides needed for hypothetical spent fuel reprocessing facilities has been estimated by assuming some reasonably conservative assumptions (Soelberg 2008):

- Compliance to the dose limits depends on the facility size and processing rate; stack parameters such as stack gas velocity, composition, and temperature; stack gas radionuclide concentrations; and air dispersion parameters including meteorological conditions. These are site-specific conditions that need to be considered for detailed analysis for any single site. An analysis of compliance to dose limits was done assuming a hypothetical case described below to estimate order-of-magnitude control requirements for air emissions of gaseous radionuclides based on dose limits.

- A maximum dose limit per nuclide of $0.1 \mathrm{mrem} / \mathrm{year}$ was conservatively assumed to ensure that the sum total dose from all emitted radionuclides (or iodine alone, as applicable) are within the total dose limit, regardless of whether a facility is a federal or NRC-licensed facility. Further complicating the compliance to regulatory emission limits is the possibility that some facilities may have more than one emission point (stack); the emission limits apply to emissions from all stacks sum together. DOE facilities with multiple emission points typically administratively limit the dose from emissions from any single stack to less than the $10 \mathrm{mrem} / \mathrm{year}$ limit, to ensure that the total dose from all stacks summed together does not exceed this limit. 
Table 3. Regulations governing radionuclide air emissions in the U.S.

\begin{tabular}{|c|c|c|c|}
\hline Facility or process & $\begin{array}{l}\text { Dose equivalent to public, } \\
\text { mrem/year }\end{array}$ & $\begin{array}{c}\text { Max fuel cycle emissions } \\
\text { per GWyr energy } \\
\text { produced }\end{array}$ & $\begin{array}{l}\text { Ambient air concentration } \\
\text { at site boundary, } \mathrm{uCi} / \mathrm{ml}\end{array}$ \\
\hline $\begin{array}{l}\text { DOE facilities, } \\
40 \text { CFR } 61 \text { Subpart H } \\
\text { (40 CFR 61.92) }\end{array}$ & $\begin{array}{l}10 \text { (total from all } \\
\text { radionuclides) }\end{array}$ & - & - \\
\hline $\begin{array}{l}\text { Federal facilities (not } \\
\text { NRC licensees, not } \\
\text { covered by } 40 \text { CFR } 61 \\
\text { Subpart H; does not apply } \\
\text { to some others) } \\
40 \text { CFR } 61 \text { Subpart I } \\
40 \text { CFR 61.102) }\end{array}$ & $\begin{array}{l}10 \text { (total) } \\
3 \text { (from iodine) }\end{array}$ & - & 一 \\
\hline $\begin{array}{l}\text { Uranium fuel cycle } \\
40 \text { CFR } 190 \text { Subpart B } \\
\text { (40 CFR 190.10) }\end{array}$ & $\begin{array}{l}25 \text { (whole body) } \\
75 \text { to thyroid } \\
25 \text { to any other organ }\end{array}$ & $\begin{array}{l}\text { Kr-85: } 50,000 \mathrm{Ci} \\
\text { I-129: } 5 \mathrm{mCi} \\
\text { Pu-239: } 0.5 \mathrm{mCi} \\
\text { (including all alpha- } \\
\text { emitting radionuclides } \\
\text { with half-lives }>1 \text { year) }\end{array}$ & - \\
\hline $\begin{array}{l}\text { NRC licensees (10 CFR } \\
20.1301,1302 \text {, App. B) }\end{array}$ & 100 (total) & - & $\begin{array}{l}\mathrm{H}-3: 1.0 \mathrm{E}-9 \text { (unlisted) } \\
\mathrm{C}-14 \text { as } \mathrm{CO}_{2}: 3.0 \mathrm{E}-7 \\
\mathrm{Kr}-85: 7.0 \mathrm{E}-7 \\
\mathrm{I}-129: 4.0 \mathrm{E}-11\end{array}$ \\
\hline
\end{tabular}

- Air emissions control for compliance to uranium fuel cycle limits, which are independent of dose but are based on the total air emissions of Kr-85, I-129, and Pu-239 (including all alpha-emitting radionuclides with half-lives $>1$ year), were estimated assuming that no other parts of the uranium cycle contribute significantly to emissions of these radionuclides).

- A 10 times the safety factor was applied to ensure regulatory compliance during reasonable process variations that could result in periodic increases and decreases in radionuclide air emissions (to avoid planning to just exactly meet the limits, which could result in occasional regulatory noncompliance due to process variations).

Figure 7 shows estimated system removal factors for gaseous radionuclides for hypothetical spent fuel reprocessing facilities. The horizontal lines for Kr-85 and I-129 removal efficiency (that are constant regardless of spent fuel reprocessing rate) are based on the uranium fuel cycle emission limits. The sloped lines that increase with increasing spent fuel processing rate are based on dose to a Maximally Exposed Individual (MEI), which depends on processing rate, stack parameters, and air dispersion modeling.

Depending on the reprocessing facility size, gaseous fission products may require the following ranges of air emissions control for spent fuel separations facilities sized up to 1,000 MTIHM/year:

- I-129: 1000-10,000 removal factor (99.9-99.99\% removal efficiency)

- H-3: 10-1,000 removal factor (90-99.9\% removal efficiency)

- Kr-85: 10-100 removal factor (0-99\% removal efficiency)

- C-14: Perhaps none. 


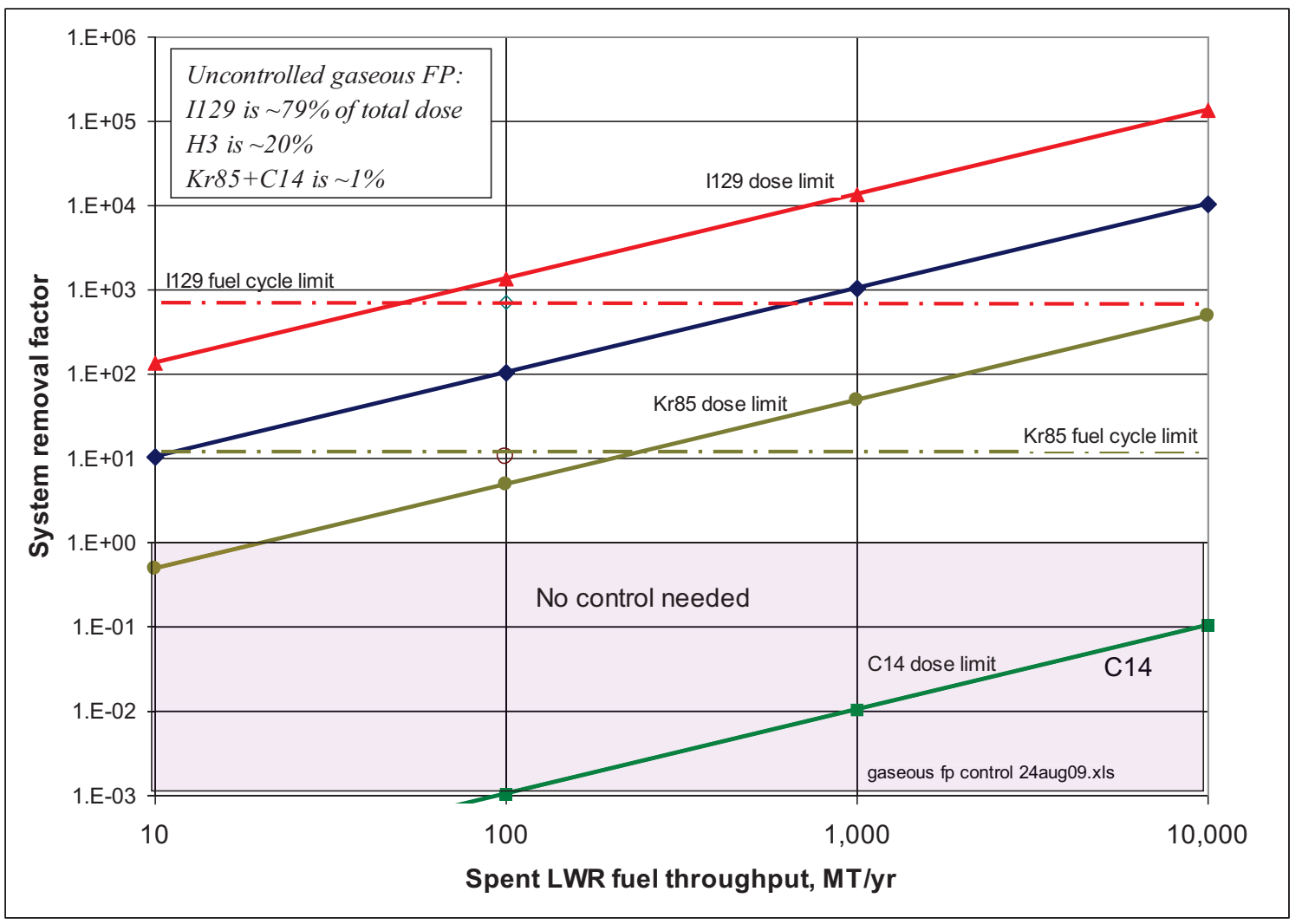

Figure 7. Estimated system removal factors needed to comply with air emissions regulations for spent fuel reprocessing facilities.

The air dispersion modeling was done using CAP88-PC3 (U.S. EPA 2006) provided by the U.S. Environmental Protection Agency (EPA) to determine compliance to 40 CFR 61, "National Emission Standards for Hazardous Air Pollutants" (NESHAPS). This model calculates the estimated air concentrations for species emitted from a stack to which the MEI is exposed. The MEI is the hypothetical individual standing on the ground at a distance downwind of the stack at a distance calculated by the air dispersion model to be where the plume just hits the ground, as shown in Figure 8. Ground air concentrations closer to the stack than this distance are lower than the concentrations at this distance because the plume has not yet reached the ground. Ground air concentrations further from the stack than this distance are also lower than the concentrations at this distance because the ambient air becomes more diluted the farther the distance from the stack becomes. In the case of this model, the MEI distance from the stack was calculated to be about 800 meters. Assumptions used in this air dispersion modeling were:

- The spent fuel source term was 4.4\% enriched, 51 GWD/MTIHM burnup, 10-year cooled LWR fuel. The ORIGEN model was used to estimate the spent fuel composition.

- The hypothetical stack was 120 feet high, with a typical plume rise.

- The rural CAP88 agricultural input maximized ingestion dose (which is significant for H-3 and I129).

- $\quad$ 10-year meteorological data for the Idaho National Laboratory was used. A dispersion factor (X/Q) of $7.7 \mathrm{E}-07 \mathrm{~s} / \mathrm{m}^{3}$ was calculated using these meteorological data. This factor attenuates the stack gas emissions to determine the dose to the MEI. Other site-specific meteorological data would result in different dispersion factors, but this value is conservatively high and generally consistent with dispersion factors from other sites that were reviewed during this evaluation. 
Figure 9 shows how the estimated system removal factors for gaseous radionuclides decrease as spent fuel ages prior to reprocessing, for an $800 \mathrm{MTIHM} / \mathrm{year}$ facility. The system removal factor needed for I129 decreases slowly, because of the long I-129 half life, and is not impacted by SNF aging. Current estimates suggest that the $\mathrm{C}-14$ emissions need not be controlled, although if they had to be, the long C14 half life would also not enable any systems removal benefit from SNF aging. Both H-3 and Kr-85 have short enough half lives that aging between 30 and 70 years could eliminate the need to control $\mathrm{Kr}-85$ emissions (depending on the 10 times the safety factor included in the calculations); aging between about 90 and 140 years could eliminate the need to control H-3 emissions. This could simplify the reprocessing facility and would eliminate two waste streams from current reprocessing designs.

The estimated system removal factors shown in Figure 9 for an 800 MTIHM/year facility are all based on dose limits. Figure 7 shows that the estimated system removal factors needed for regulatory compliance can be lower for smaller facilities, as long as the system removal factors are based on dose and not fuel cycle limits. A facility with a smaller reprocessing rate of about $100 \mathrm{MTIHM} / \mathrm{year}$ would not require $\mathrm{Kr}-85$ control for fuel cooled at least 30-40 years, because smaller through-put facilities can have lower system removal factors and still meet the dose limits. The controlling $\mathrm{Kr}-85$ emission limit for facilities smaller than about $200 \mathrm{MTIHM} /$ year is based on the fuel cycle limit and not the dose limit.

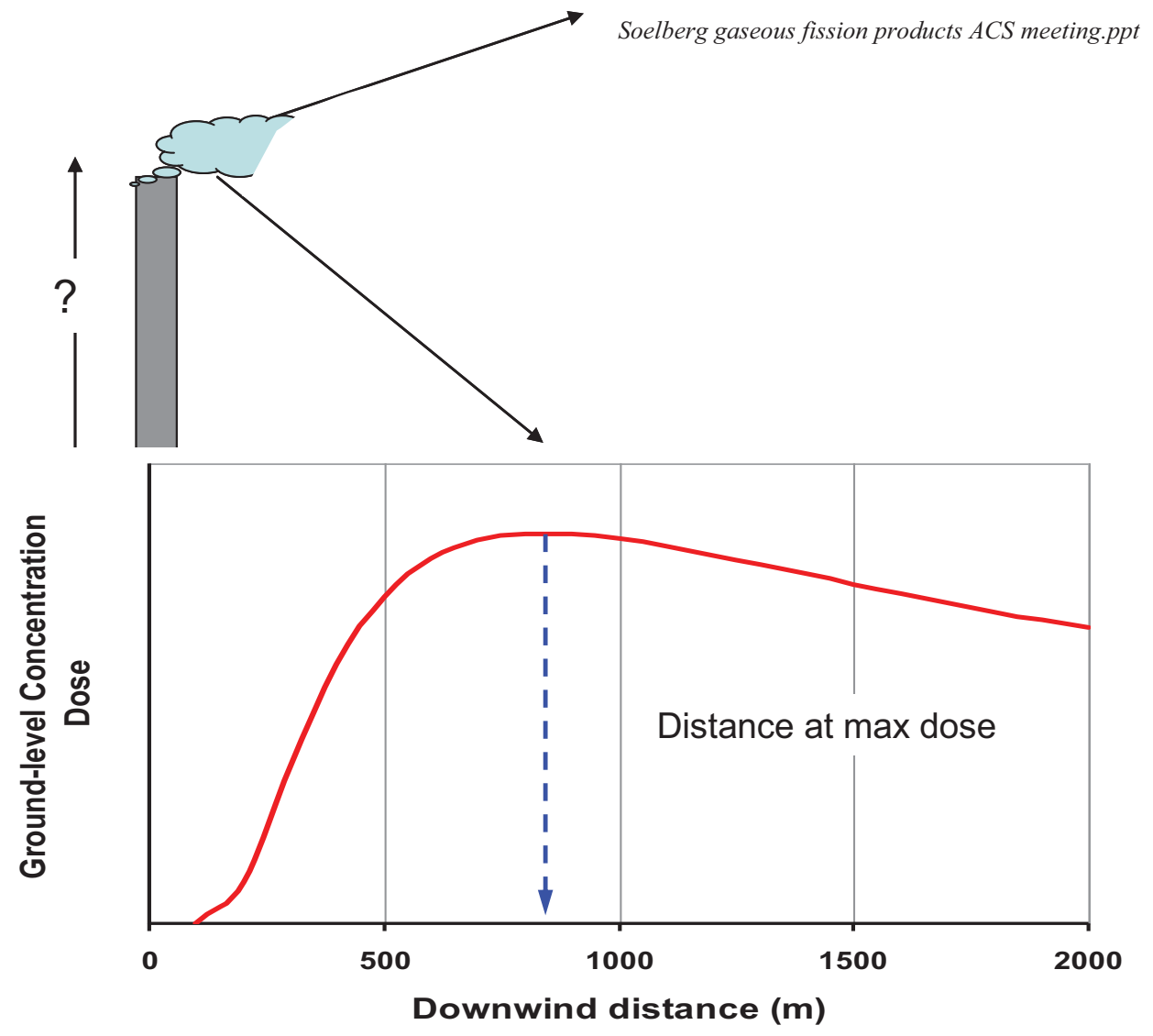

Figure 8. Hypothetical air dispersion model, resulting in this case in a calculated MEI distance from the stack of $800 \mathrm{~m}$ (Soelberg 2008). 


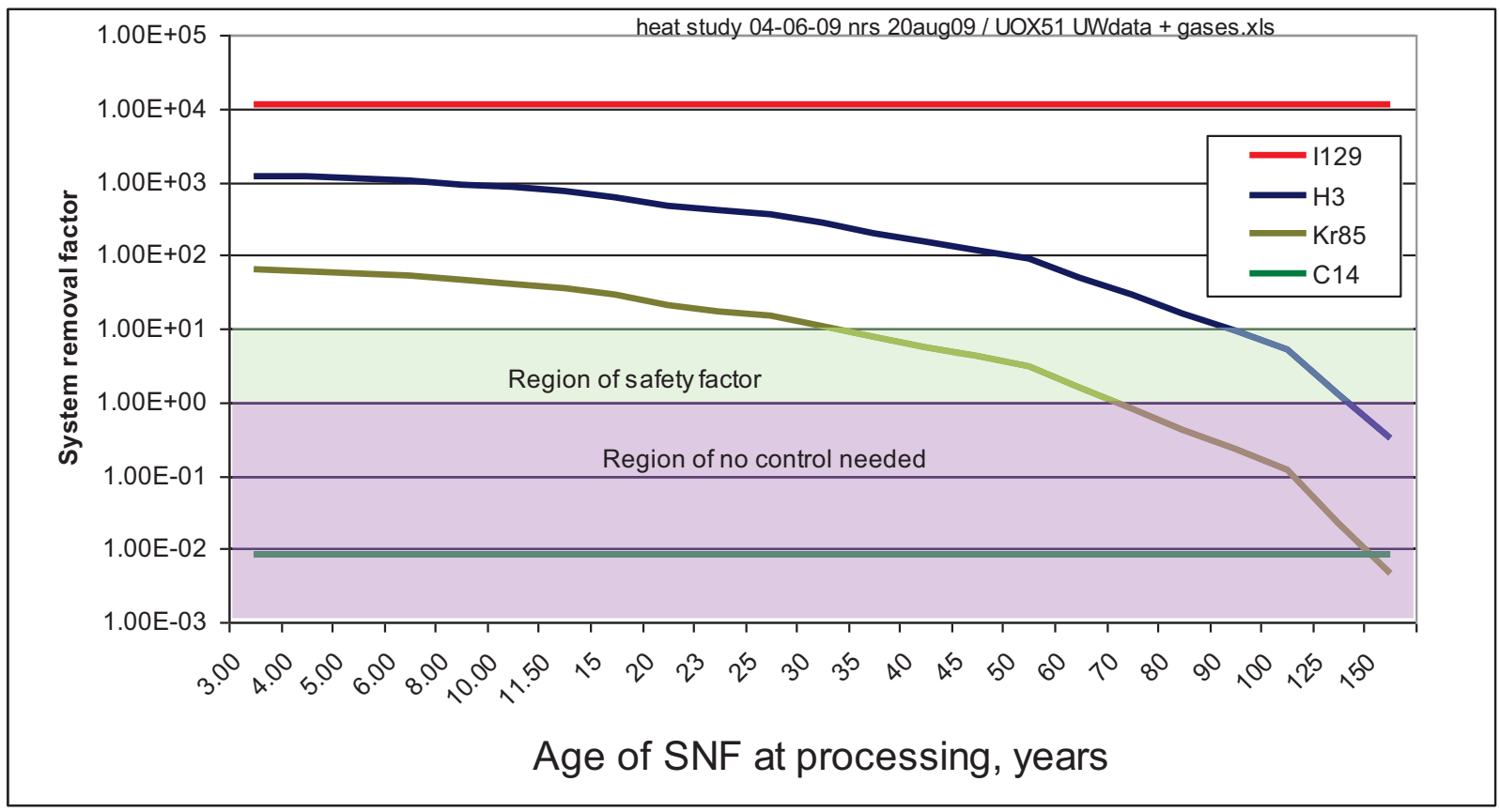

Figure 9. SNF aging prior to reprocessing and the system removal factor for gaseous fission products.

\section{REPOSITORY VENTILATION TO MEET TEMPERATURE LIMITS AND INCREASE REPOSITORY LOADING FACTORS}

The prior section addressed how SNF aging and separations of high-heat isotopes can be used to reduce disposal costs and increase repository loading by increasing the waste loading in a borosilicate glass waste form while still meeting the glass waste form temperature and durability requirements. This section addresses how SNF aging and separations, along with repository ventilation cooling, can be used to increase the repository loading which is limited by repository thermal limits.

Management of decay heat is potentially the most important factor limiting the loading density of SNF (or HLW waste separated from SNF) in geologic storage, if high-decay-heat isotopes are still present in the waste. Shortly following discharge from a reactor, heating from shorter-lived isotopes of CsSr, TMFP, actinides, and lanthanides dominate or contribute significantly to spent fuel decay heating for several hundred years. However, from the standpoint of long-term geologic storage, heat generated by long-lived isotopes of actinides $\mathrm{Pu}$ and $\mathrm{Am}$ is of paramount importance.

A systematic study has been performed using detailed thermal analyses to evaluate a heatmanagement strategy for a geologic repository where the decay heat from short-lived isotopes is "accommodated" by combinations of disposal delays followed by periods of ventilation. These calculations assume the examples of $50 \mathrm{GWD} / \mathrm{MT}$ spent fuel from a PWR and the well-developed design of the Yucca Mountain Repository. Other modeling assumptions and calculation methods are reported in Wigeland's report (2006). Loading limits (and benefits achieved) are computed for cases where (a) disposed spent fuel has between 0 and $99.9 \%$ of its $\mathrm{Pu}$ and Am content removed for recycle, (b) disposal in the repository takes place between 50 and 150 years following discharge from the reactor, and (c) waste packages are cooled by ventilating airflow for an additional time period between 50 to 150 years. Other long-lived, higher heat isotopes such as some of the minor actinides are not included in this analysis for simplicity, since their heat impact is small compared to the Pu and Am. 
The 100-300 year time periods spanned by included combinations of disposal delays and ventilation periods intentionally encompass the lifetimes of the major short-lived heat-generating isotopes. For simplicity, assumed removal fractions for $\mathrm{Pu}$ and Am apply equally to both elements. Otherwise, the remaining $\mathrm{Pu}+\mathrm{Am}$ heat source could be very sensitive to when these removals take place.

Results of these analyses are shown in Table 4. Linear loading limits are reported as " $\mathrm{GWD} / \mathrm{m}$ " (i.e., the upper limit to generated energy [GWD] whose waste can be stored in 1 meter of drift). The repository thermal limits are $200^{\circ} \mathrm{C}$ at the storage drift wall and $96^{\circ} \mathrm{C}$ in the rock midway between storage drifts. Which one of these temperature limits control the loading reflects the relative importance of (a) shortterm decay heating at the time of disposal and after ventilation ceases, and (b) long-term decay heating of bulk rock over $1,000+$ years.

The Reference Case 1 corresponds closely to the nominal direct disposal analysis of spent PWR fuel after a 25-year delay plus a 75-year ventilation, described in Wigeland's report (2006). Results for both analyses are nearly identical. Importantly, as also reported in Wigeland's 2006 report, results of Cases 29 indicate that incremental increases in the loading limits (i.e., the storage "benefits") are small when the age of the SNF prior to disposal is increased to 150 years, and/or the duration of forced air repository ventilation is increased to 150 years. While this total 300 year time is long enough to manage the heat from for the shorter-lived, high-heat isotopes until they are considerably decayed, the long-term heating of the mid-drift rock by the $\mathrm{Pu}$ and $\mathrm{Am}$ is the controlling limit and limits the maximum possible loading.

Figure 10 for Case 1 illustrates that repository temperatures change little until the ventilation is turned off, at which time both the drift wall and mid-drift rock temperatures increase faster due to heat from the waste that is no longer removed by ventilation. In this reference case the maximum loading is limited by the mid-drift rock temperature, which reaches the $96^{\circ} \mathrm{C}$ limit at 1,600 years after emplacement. The drift wall temperature remains below the limit of $200^{\circ} \mathrm{C}$ at all times.

Cases 10-36 show that significant loading benefits can be achieved only when large fractions of $\mathrm{Pu}$ and Am are removed. For the minimal 100 year delay + ventilation (nominal Yucca Mountain) strategy, Table 4 shows loading can increase by factors up to $\sim 5$ (Cases 10, 19, and 28) with minimum SNF aging and repository ventilation durations. The greatest possible storage benefit of $\sim 80$ is achieved for Case 36, which has the highest level (99.9\%) of Pu and Am removal, and the longest SNF aging and ventilation periods. Figure 11 shows for Case 36 that the drift wall temperature is not reached, and the mid-drift rock temperature is still the basis for the loading limit, approaching $96^{\circ} \mathrm{C}$ at about 6,000 years.

Other considerations, in particular the waste loading in a borosilicate glass, and dose, will limit the actual storage benefit to less than $\sim 80$ times for Case 36 . This case exemplifies that multiple factors should be considered in evaluations of possible methods to increase the repository waste loading. More copmrehensive evaluations should consider recalculation of repository thermal and dose limits based on alternative repository geologies and designs, and disposal of HLW from separations instead of SNF assemblies.

In every case, the "Time" column of Table 4 indicates when the controlling limit is reached following emplacement. If the limit is reached during the ventilation period, then additional loading benefit can be achieved by increasing the SNF aging time. If the limit is reach after, but close to the end of the ventilation period, additional loading benefit can be achieved by further ventilation or disposal delay. Figures 12 and 13 (for Cases 28 and 32) show that, for the same 99.9\% removal of Pu and Am as in Figure 11 (Case 36), decreasing aging and ventilation times lowers the loading benefit factors, changes the controlling limit from the mid-drift rock temperature to the drift wall temperature, and shortens the time until the limit is reached. Figure 13 shows the same spent fuel waste again, but with 100 year aging and ventilation (Case 32). In Figure 12 (aging and ventilation for the minimum 50 years each), the limiting temperature is reached at the drift wall about 10 years after the ventilation is turned off, resulting 
in a loading benefit of $\sim 5$. Figure 13 (aging and ventilation for 100 years each) the limiting temperature is reached at the drift wall about 2 years following emplacement, and the loading benefit is increased to $\sim 36$.

Table 4. Separations, disposal, and ventilation study; 50 GWD/MTIHM PWR spent fuel.

\begin{tabular}{|c|c|c|c|c|c|c|c|}
\hline Separations & $\begin{array}{c}\text { Disposal } \\
\text { (Years) }\end{array}$ & $\begin{array}{c}\text { Ventilation } \\
\text { (Years) }\end{array}$ & $\begin{array}{c}\text { Storage limit } \\
(\mathrm{GWD} / \mathrm{m})\end{array}$ & $\begin{array}{l}\text { Storage } \\
\text { "benefit" }\end{array}$ & $\begin{array}{c}\text { Controlling } \\
\text { limit }\end{array}$ & $\begin{array}{l}\text { Time } \\
\text { (years) }\end{array}$ & $\begin{array}{c}\text { Case } \\
\text { number }\end{array}$ \\
\hline \multirow{9}{*}{$\begin{array}{l}\text { None: } \\
\text { (Direct } \\
\text { Disposal) }\end{array}$} & \multirow{3}{*}{50} & 50 & 59 & Ref. $=1.0$ & \multirow{3}{*}{$\begin{array}{l}\text { Between } \\
\text { Drifts }\end{array}$} & 1,600 & 1 \\
\hline & & 100 & 64 & 1.1 & & 1,800 & 2 \\
\hline & & 150 & 68 & 1.2 & & 2,000 & 3 \\
\hline & \multirow{3}{*}{100} & 50 & 65 & 1.1 & \multirow{3}{*}{$\begin{array}{l}\text { Between } \\
\text { Drifts }\end{array}$} & 1,800 & 4 \\
\hline & & 100 & 69 & 1.2 & & 2,000 & 5 \\
\hline & & 150 & 72 & 1.2 & & 2,200 & 6 \\
\hline & \multirow{3}{*}{150} & 50 & 69 & 1.2 & \multirow{3}{*}{$\begin{array}{l}\text { Between } \\
\text { Drifts }\end{array}$} & 2,000 & 7 \\
\hline & & 100 & 73 & 1.2 & & 2,200 & 8 \\
\hline & & 150 & 76 & 1.3 & & 2,400 & 9 \\
\hline \multirow{9}{*}{$\begin{array}{l}98 \% \text { of } \mathrm{Pu} \\
\text { and Am } \\
\text { Removed }\end{array}$} & \multirow{3}{*}{50} & 50 & 283 & 4.8 & \multirow{3}{*}{ Drift Wall } & 60 & 10 \\
\hline & & 100 & 632 & 11 & & 2 & 11 \\
\hline & & 150 & 632 & 11 & & 2 & 12 \\
\hline & \multirow{3}{*}{100} & 50 & 813 & 14 & \multirow{3}{*}{ Drift Wall } & 70 & 13 \\
\hline & & 100 & 1,824 & 31 & & 120 & 14 \\
\hline & & 150 & 2,022 & 34 & & 6 & 15 \\
\hline & \multirow{3}{*}{150} & 50 & 1,973 & 34 & Drift Wall & 70 & 16 \\
\hline & & 100 & 2,194 & 37 & \multirow{2}{*}{$\begin{array}{l}\text { Between } \\
\text { Drifts } \\
\end{array}$} & 4,000 & 17 \\
\hline & & 150 & 2,288 & 39 & & 4,000 & 18 \\
\hline \multirow{9}{*}{$\begin{array}{l}99 \% \text { of } \mathrm{Pu} \\
\text { and Am } \\
\text { Removed }\end{array}$} & \multirow{3}{*}{50} & 50 & 289 & 4.9 & \multirow{3}{*}{ Drift Wall } & 60 & 19 \\
\hline & & 100 & 636 & 11 & & 2 & 20 \\
\hline & & 150 & 636 & 11 & & 2 & 21 \\
\hline & \multirow{3}{*}{100} & 50 & 861 & 15 & \multirow{3}{*}{ Drift Wall } & 70 & 22 \\
\hline & & 100 & 2,062 & 35 & & 2 & 23 \\
\hline & & 150 & 2,062 & 35 & & 2 & 24 \\
\hline & \multirow{3}{*}{150} & 50 & 2,247 & 38 & Drift Wall & 70 & 25 \\
\hline & & 100 & 3,069 & 52 & \multirow{2}{*}{$\begin{array}{l}\text { Between } \\
\text { Drifts }\end{array}$} & 4,000 & 26 \\
\hline & & 150 & 3,187 & 54 & & 5,000 & 27 \\
\hline \multirow{9}{*}{$\begin{array}{l}99.9 \% \text { of } \mathrm{Pu} \\
\text { and Am } \\
\text { Removed }\end{array}$} & \multirow{3}{*}{50} & 50 & 295 & 5.0 & \multirow{3}{*}{ Drift Wall } & 60 & 28 \\
\hline & & 100 & 640 & 11 & & 2 & 29 \\
\hline & & 150 & 640 & 11 & & 2 & 30 \\
\hline & \multirow{3}{*}{100} & 50 & 908 & 16 & \multirow{3}{*}{ Drift Wall } & 60 & 31 \\
\hline & & 100 & 2,099 & 36 & & 2 & 32 \\
\hline & & 150 & 2,099 & 36 & & 2 & 33 \\
\hline & \multirow{3}{*}{150} & 50 & 2,558 & 44 & Drift Wall & 70 & 34 \\
\hline & & 100 & 4,689 & 80 & Between & 5,000 & 35 \\
\hline & & 150 & 4,862 & 83 & Drifts & 6,000 & 36 \\
\hline
\end{tabular}

Short-term decay heat determines the loading limits where Table 4 indicates the "drift wall" temperature limit of $200^{\circ} \mathrm{C}$ is controlling. Under these conditions, to be most effective, emplacement should be delayed and/or ventilation should be extended to maintain drift wall temperature below the $200^{\circ} \mathrm{C}$ limit. This ensures that the temperature limit associated with long-term decay heating of bulk rock is controlling, as in cases $17,18,26,27,35$, and 36 . 


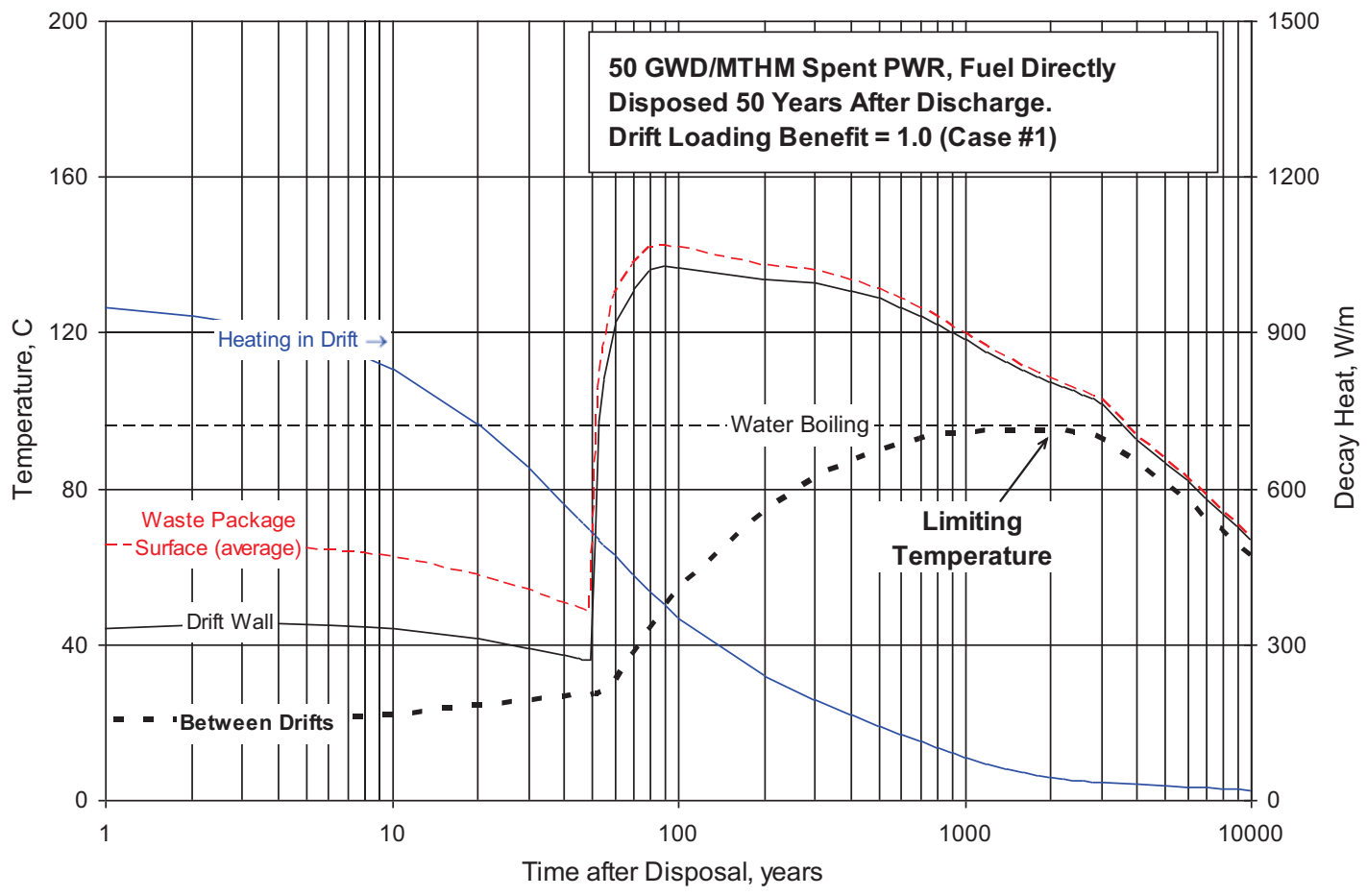

Figure 10. Transient thermal response for reference direct disposal of PWR spent fuel (Case 1).

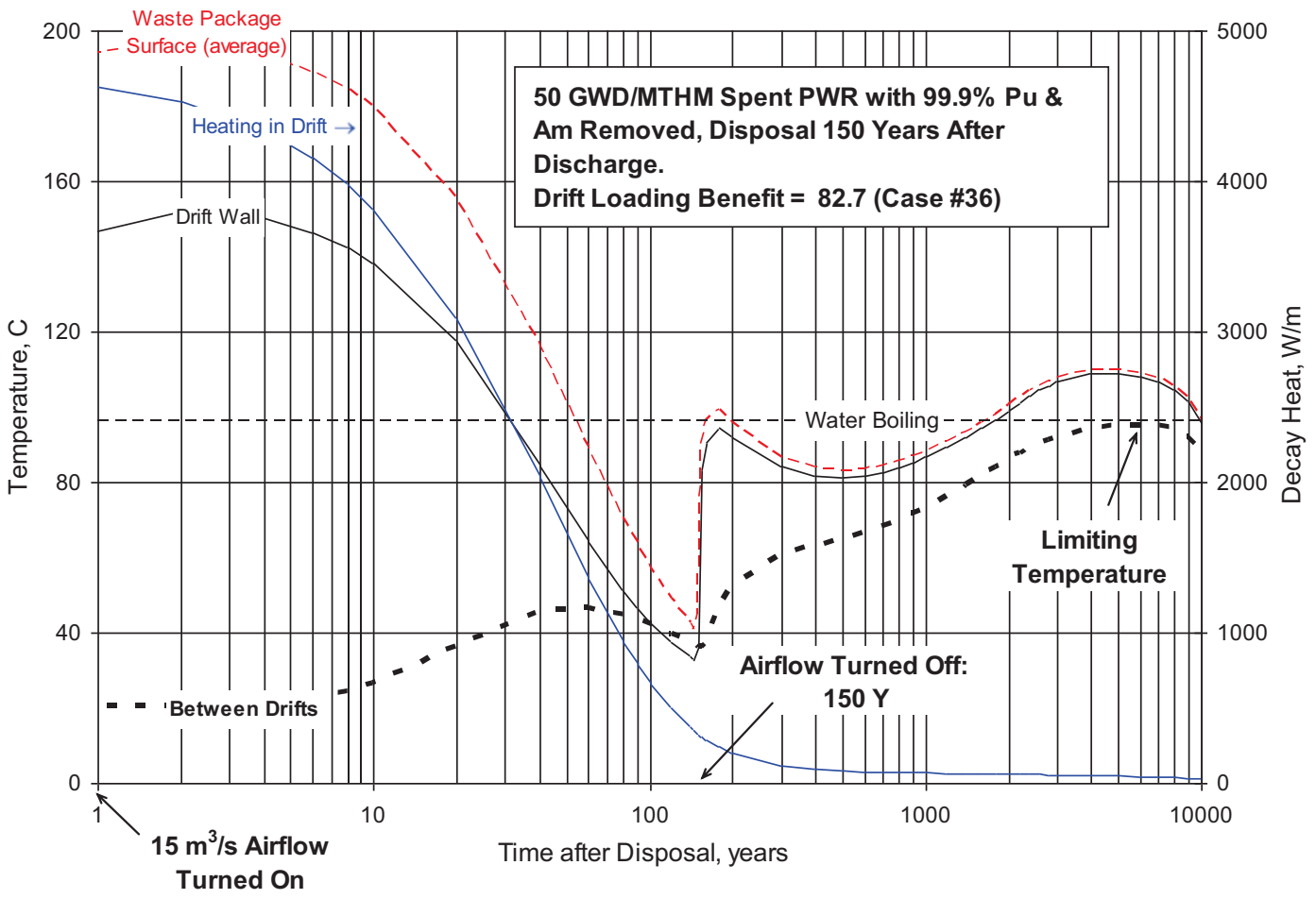

Figure 11. Transient thermal response for direct disposal of PWR spent fuel with $99.9 \%$ of Pu and Am removed, 150-year disposal delay, and 150-year ventilation (Case 36). 


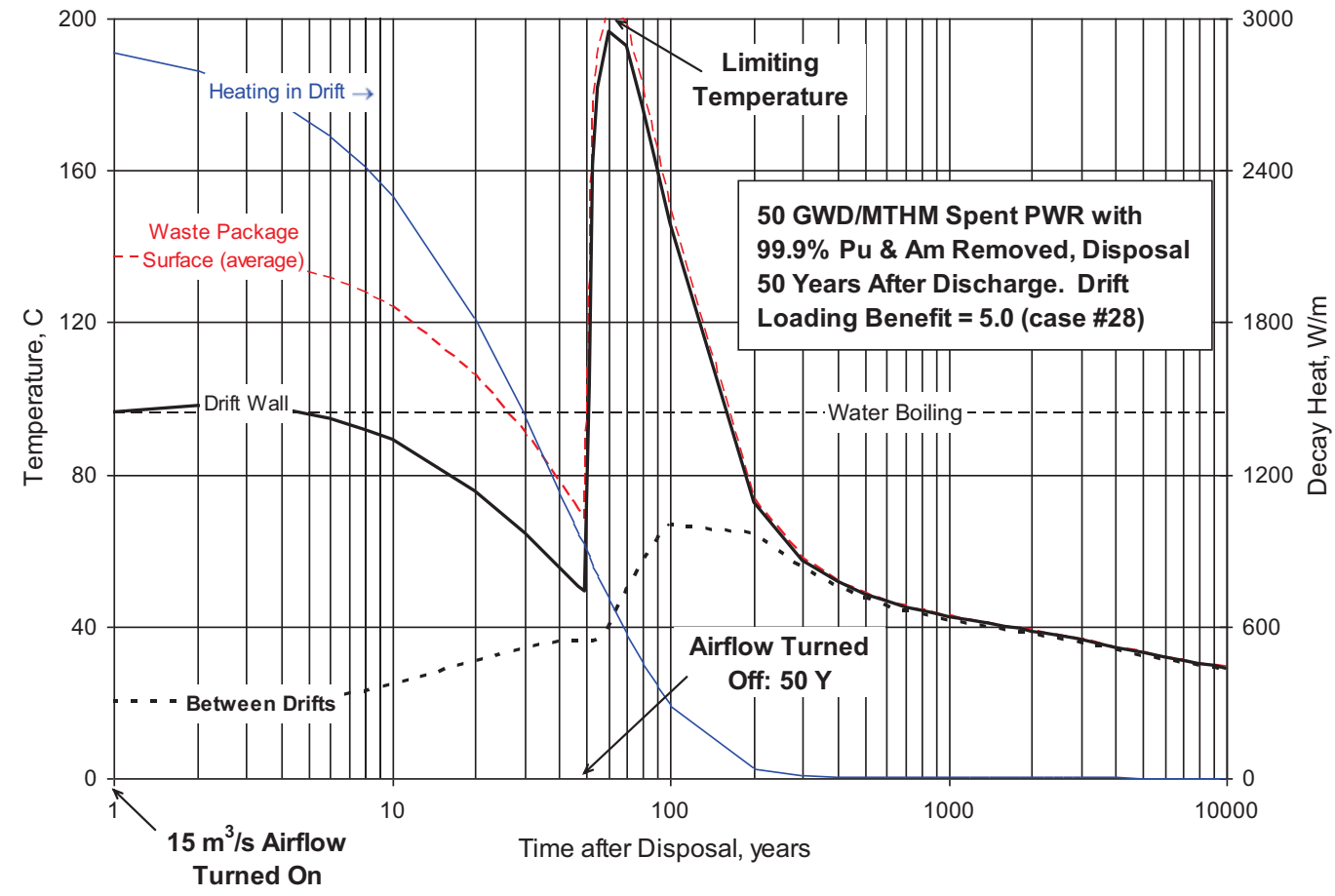

Figure 12. Transient thermal response for direct disposal of PWR spent fuel with $99.9 \%$ of Pu and Am removed. Same as Figure 11, but with minimum 50-year disposal delay and ventilation (Case 28).

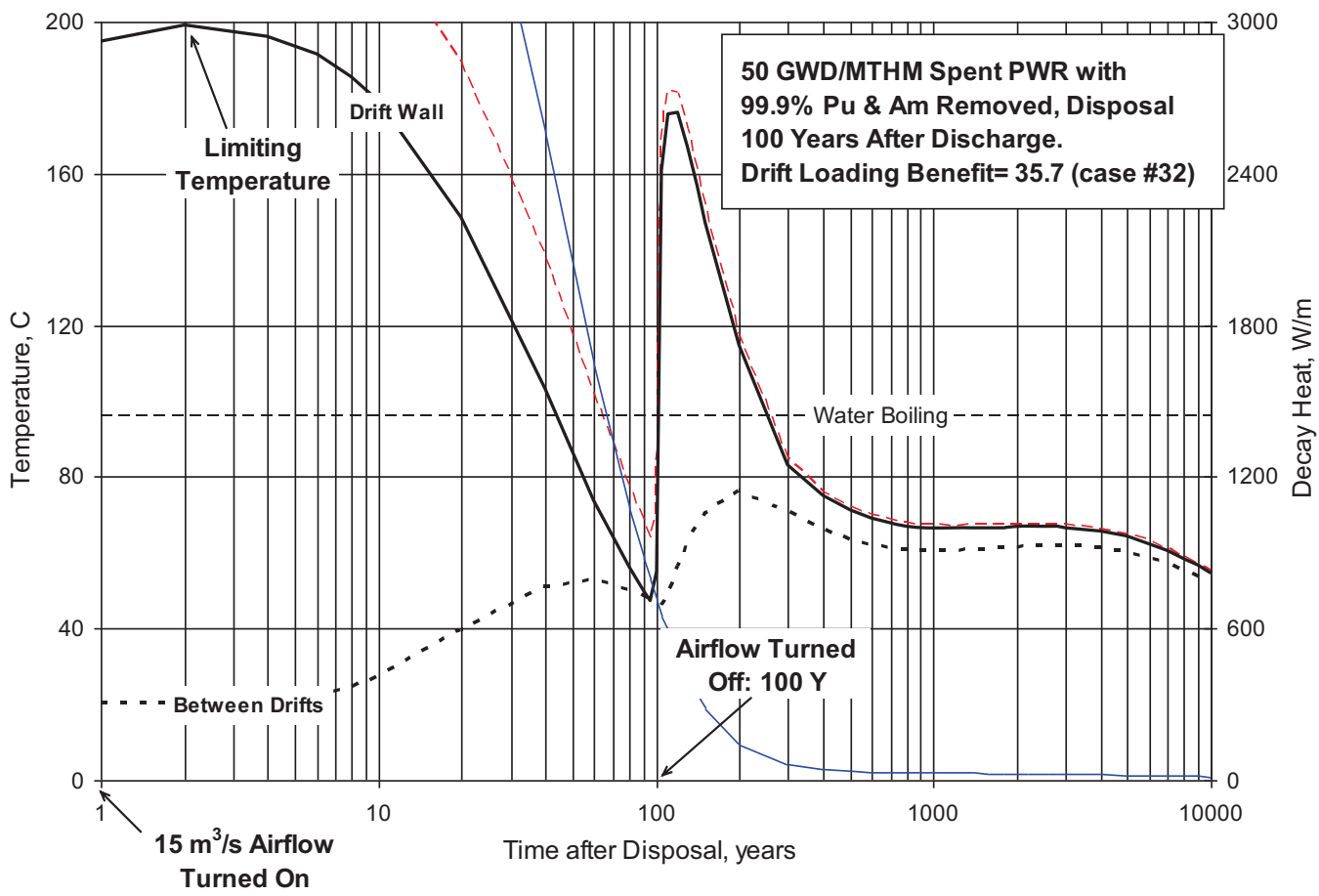

Figure 13. Transient thermal response for direct disposal of PWR spent fuel with $99.9 \%$ of Pu and Am removed. Same as Figure 11, but with 100-year disposal delay and ventilation (Case 32). 
An important conclusion of this study is that, following removal of $\mathrm{Pu}$ and $\mathrm{Am}$, the operating strategies of disposal delay and extended ventilation can allow substantial loading increases commensurate with increases computed in Wigeland's 2006 report through removal of short-term decay heat sources from $\mathrm{Cs}, \mathrm{Sr}$, and $\mathrm{Cm}$. Alternatively, repository design changes such as increasing the drift diameter (to reduce the drift wall temperature in cases that are limited by the drift wall temperature) or placing the drifts farther apart (to lower the mid-drift rock temperature in cases limited by the mid-drift rock temperature) could also increase the repository loading.

\section{CONCLUSIONS AND RECOMMENDATIONS}

Several studies have been performed in recent years to evaluate options for managing wastes generated from recycling spent nuclear fuel SNF. This Heat Management Trade Study has been performed in 2008-2009 to expand on these prior studies in continued efforts to analyze and evaluate options for cost-effectively managing SNF reprocessing wastes.

Until February 2009, SNF and HLW in the U.S. were destined for permanent geological disposal in the planned nuclear waste repository at Yucca Mountain in Nevada. Plans for the Yucca Mountain repository have now been stopped while other alternatives for handling SNF in the U.S. are being investigated.

Regardless of the geological repository architecture, thermal limits are expected to be imposed on geologic repository designs to mitigate consequences of heating the repository caused by decay heat generation from the emplaced HLW. The Yucca Mountain thermal limits, used in this study prior to February 2009, continue to be used because (a) these thermal limits have been developed during the Yucca Mountain design process, (b) there are no thermal limits for other potential repositories to base this study on, and (c) the results, based on the Yucca Mountain characteristics, are still (most likely) instructive and illustrative regardless of the eventual HLW repository situation.

The primary objective of the Heat Management Trade Study was to evaluate strategies to most costeffectively increase the loading of waste in the repository without exceeding the temperature limits. Dose and volume limits are not specifically considered in this study, although dose is discussed qualitatively. This objective is based on the premise that either the legislated 70,000 MT limit in the NWPA could be increased or eliminated, such as could occur when a second repository becomes available. Parameters that were varied in this study include:

- Age of the SNF prior to reprocessing and prior to emplacement in the repository

- Uranium, plutonium, and minor actinide (MA) separation from the SNF for recycle, and separation efficiencies

- Fuel value of the recycled Pu and MA

- Length of time that active ventilation is employed in the repository.

Relative differences in cost were estimated by assuming constant per-canister vitrification and disposal costs, and varying the number of canisters according to calculated waste loadings needed to meet glass heat generation and concentration limits determined for different SNF aging and separations options. The fuel value of separated fissile material was also considered. The cost impacts were used to evaluate reprocessing and waste management strategies to maximize repository benefit versus cost.

\subsection{Conclusions}

This trade study used additional parametric analyses to confirm and add to the results of prior studies. Conclusions include: 
- Both short-term and long-term heat generation can limit geological repository SNF and HLW loadings by affecting either the temperature of the waste form, waste package, or rock temperatures, all of which have temperature limits, above which the isolation of the waste from the environment could be jeopardized. Assuming a glass waste form for waste remaining after SNF separations for recycling $\mathrm{U}, \mathrm{Pu}$, and $\mathrm{MA}$, and assuming the repository design and thermal limits for Yucca Mountain, the loading efficiency for different cases of SNF aging prior to emplacement, efficiencies of $\mathrm{U}, \mathrm{Pu}$, and MA separations, and repository ventilation following emplacement can increase the repository loading until one of three limits for the waste form temperature, the drift wall temperature, or the middrift rock temperature, or chemistry (waste loading) limits for the waste form, are reached. Increasing the repository loading efficiency beyond about 1.3 times requires at least some degree of SNF separations to recycle $\mathrm{Pu}, \mathrm{Am}$, or MA, along with combinations of SNF aging prior to waste emplacement or repository cooling after emplacement. Cases with Pu, Am, MA, and UDS removal, SNF aging, and repository cooling at reasonable maximum values could increase the repository loading efficiency to about 3 times when borosilicate glass is assumed to be a single waste form. Increasing the loading efficiency above about 3 times is only possible with additional changes such as changing the waste form to allow higher waste loadings (based on chemistry and temperature limits) or modifying the repository design or thermal limits.

- The repository waste loading efficiency can be increased by a factor of about 1.3 through only aging the SNF or extending ventilation duration (up to a total of 300 years), without any SNF separations and recycle. SNF aging and repository ventilation for reasonable time periods can mitigate much of the relatively high heat generation from the high-heat, shorter-lived isotopes in the Ln, TMFP, and $\mathrm{Cs} / \mathrm{Sr}$ groups of elements. The waste loading increase is limited to about 1.3 without any separations because the high-heat, longer-lived $\mathrm{Pu}$ and MA isotopes that remain in the waste cause the mid-drift rock temperature to reach the $96^{\circ} \mathrm{C}$ temperature limit during the years in the repository after ventilation is stopped.

- SNF aging prior to disposal of at least 20 years, without separations of the Pu and MA, would enable the waste loading in a borosilicate glass waste form to increase by about 2 times, thereby potentially increasing the repository waste loading efficiency. However, since the repository temperature limits restrict the maximum repository loading increase to about 1.3 times (unless $\mathrm{Pu}$ and MA are separated), increasing the glass waste loading by up to 2 times provides no added benefit except that the vitrification and disposal costs (estimated on a per-canister basis) can be reduced.

- Separating Pu and the MA (for recycle) reduces the long-term heat impact on the repository. This enables higher repository waste loading efficiencies that are limited by the long-term increase in the mid-drift rock temperature. A maximum loading increase of abut 80 times is accomplished by the combined total 300-year SNF aging and ventilation times, plus 99.9\% removal of Pu and Am. Smaller loading increases are possible with shorter aging and ventilation times and less-efficient $\mathrm{Pu}$ and Am removal.

- For borosilicate glass waste forms, the maximum possible loading increase of about 80 times indicated by the repository heat analysis for cases of SNF aging, repository cooling, and Pu/MA separations cannot be realized (unless the repository drift design and/or the linear waste loading in the drifts are also changed) because the glass waste loading increase is limited to about 2 times due to the concentrations of TMFP and noble metals. If, however, the UDS remaining after aqueous separations are removed from the waste and otherwise managed, then the glass waste loading can increase by about 3 times. So, unless the repository design is changed, or other waste forms besides borosilicate glass are assumed, the maximum repository loading increase achievable through reasonable SNF aging and repository cooling, efficient (99.9\%) removal of Pu and MA, and 100\% removal of UDS, is not about 80 times, but only 3 times. 
- Recycling Pu and MA, and separating the UDS from aqueous separations for alternative management, provides economic value in the fuel value of recycled fuel, and enables up to a 3-time decrease in the amount of borosilicate glass assumed as the waste form for the residual HLW. The reduction in the glass amount reduces the costs of vitrification and waste disposal. Using these cost metrics, combined with aging the SNF for up to 40 years (even though this results in a fractional loss in the recycled fuel value), provides an annual cost benefit of up to about $\$ 250$ million per year for an aqueous SNF separations facility operating at $800 \mathrm{MTIHM} /$ year, or about \$310,000/MTIHM processed. This value can help offset the SNF separations costs. Not considered in this analysis are such factors as (a) the time value of money, (b) costs for alternative UDS management, and (c) future economics of new uranium or other new fuel resources that would affect the future value of recycled fuel.

- In addition to decreasing the number of canisters to be disposed, thereby reducing the cost for treatment and disposal, aging SNF prior to reprocessing lowers the radiation levels of the SNF. Aged SNF has lower radioactivity than does greener SNF. This lowers the amount of shielding needed for temporary storage, transport, and processing facilities, lowers the dose hazard to personnel, and lowers the amount of damaging radiation that equipment is exposed to. The lower radiation levels may result in handling, storage, processing, and transportation cost savings that are not included in this study.

- Aging SNF prior to reprocessing, or recovering some groups of radionuclides from SNF during reprocessing, can lower the remaining radiotoxicity of the waste when emplaced in a repository. Current calculations set the dose risk from direct disposal of SNF in the Yucca Mountain repository at $0.24 \mathrm{mrem} /$ year, which is about 60 times lower than the allowable Yucca Mountain limit of 15 $\mathrm{mrem} /$ year. Thus, the dose risk is not the limiting factor for the amount of direct-disposed SNF that was regulatorily allowed to be disposed in Yucca Mountain. Holding all other factors that can affect the dose risk constant, SNF aging or separations processes can theoretically achieve a 60 -time repository loading efficiency factor before reaching the dose risk limit. However, SNF aging and separations both remove some of the radiotoxicity in the remaining waste by removing some of those elements that contribute to the radiotoxicity (Piet 2009). This would further increase the margin of safety for the dose risk so that dose risk is not expected to become a limiting factor for increasing repository loading through aging, ventilation, separations scenarios.

- SNF contains several radioactive fission products that tend to evolve into gaseous streams during spent-fuel reprocessing. Prior analyses have shown that C-14-laden gaseous species should not require any emissions control and still meet expected regulatory limits that would be based on dose to the public. In addition, this study indicates that SNF aging - prior to separations - between 30-70 years could eliminate the need to control Kr-85 emissions; aging between about 90-140 years could eliminate the need to control H-3 emissions. This could simplify the reprocessing facility and would eliminate two waste streams from current reprocessing designs. Control of air emissions of I-129 during reprocessing is expected to be required regardless of SNF aging times.

\subsection{Recommendations}

This study has augmented the results of prior studies through additional analyses of SNF aging, separations, and repository ventilation times. Analysis tools were developed for evaluating these parameters using metrics including costs and repository loading factors. Results show that any one of several different, and seemingly unrelated, parameters such as short-term heat generation, long-term heat generation, waste form temperature limits, repository temperature limits, and waste chemistry limits can restrict repository waste loadings. The dominance of any of these parameters can depend on the assumed scenarios. All of these parameters need to be considered in future radioactive waste management and 
disposal evaluations. Results also suggest that the value of recycled fuel be considered in evaluations of spent fuel reprocessing.

These analyses have so far been restricted to LWR spent fuels, borosilicate glass waste forms, and the Yucca Mountain repository requirements. These analyses have not considered (a) SNF separations costs in the economic evaluations; (b) the time value of money; (c) future supply and demand of raw materials for nuclear fuels; (d) management, potential recycle, and metrics of components of SNF such as the UDS, hardware, and hulls; or (e) management of radioactive wastes from operations and maintenance of a reprocessing facility. Some of these can be important issues that should be considered in future analyses.

Future analyses should include:

- Consideration of potential thermal and radiotoxicity limits that might occur for various candidate geological repository configurations besides Yucca Mountain.

- Evaluations of SNF management for fast reactors and recycled fuel reactors including Pu and MA transmutation reactors.

- Echem separations.

- More definitive separations factors for aqueous and Echem separations based on empirical results (when available) or more detailed modeling.

- Alternative waste forms besides borosilicate glass that might have higher waste loading capabilities based on higher temperature and chemistry tolerance.

- Consideration of waste forms tailored for alternative geological-repository characteristics for maximum waste immobilization.

- Evaluation of cost of compliance to repository thermal and other limits.

- Evaluations of cost trade-offs between increased degree of separations and loss of value of fuel constituents (U, Pu, MA, hulls, etc.) if they are not recovered, and cost of decay storage.

- More holistic evaluations of SNF management options. Can the residual HLW streams from SNF separations be reduced through recycling and based on heat generation and radiotoxicity (rather than labeling based on the source of the waste), and can residual waste streams meet LLW class $\mathrm{A} / \mathrm{B} / \mathrm{C} /$ Greater Than Class $\mathrm{C}$ limits for potentially less costly and more available disposal?

- Consideration of other reprocessing costs besides vitrification and disposal (that are already included).

- Accounting for costs and impacts of radioactive waste generation from reprocessing facility operations and maintenance, and spent solvents/reagents, considering how reasonable or innovative variations in waste treatment and waste minimization can reduce those waste streams.

\section{REFERENCES}

Carter, J. T., 2009, "Minor Actinide Study: Facility Descriptions and Cost Estimate Bases and Assumptions," AFCI-SYSA-AI-EC-RP-2009-000062, 2009.

Dixon, Brent, Joe Carter, Rick Geddes, Bill Halsey, Mark Nutt, Steven Piet, David Shropshire, Ruth Weiner, and Kent Williams, 2009, "Minor Actinides Trade Study Report," AFCI-SYSA-AI-MI-DV2009-00077, June 30.

Gombert II, D. et al, 2008a, "Global Nuclear Energy Partnership Integrated Waste Management Strategy Rev. 1,” GNEP-WAST-WAST-AI-RT-2008-000214, May 2008. 
Gombert, D, et.al., 2008b, “Combined Waste Form Cost Trade Study,” GNEP-SYSA-PMO-MI-DV2009-000003, November 2008.

Jones, R.H. et.al, 2008, "Management of Decay Heat from Spent Nuclear Fuel," Rev 2, GNEP-SYSAPMO-MI-DV-2008-000180, March 2008.

Piet, Steven J., Brent W. Dixon, Dirk Gombert, Edward A. Hoffman, Gretchen E. Matthern, and Kent A. Williams, 2009, "Fuel Cycle System Analysis Handbook," AFCI-SYSA-AI-MI-DV-2009-000035, June 30 .

Soelberg, Nick, Mike Abbott, Daryl Haefner, and Bob Jubin, 2008, "Gaseous Fission Product Emissions Control During Spent Nuclear Fuel Recycling," $235^{\text {th }}$ American Chemical Society National Meeting and Exposition, New Orleans, Louisiana, April 6-10, 2008.

Stillman, J. A. et al., 2004, "Follow-Up Analyses for the ANTT Review," Argonne National Laboratory, ANL-AFCI-132, September 30, 2004.

U.S. DOE, 2002, "Yucca Mountain Science and Engineering Report," Rev. 1, U.S. DOE, Office of Civilian Radioactive Waste Management, DOE/RW-0539-1, February 2002.

U.S. DOE, 2004, "Nuclear Waste Policy Act as Amended with Appropriations Acts Appended," (consisting of the Nuclear Waste Policy Act of 1982, (Public Law 97-425; 96 Stat. 2201), as amended by P.L. 100-203, Title V, Subtitle A (December 22, 1987), P.L. 100-507 (October 18, 1988), and P.L. 102-486 (The Energy Policy Act of 1992, October 24, 1992), generally codified at 42 U.S.C. 10101 and following), http://www.ocrwm.doe.gov/uploads/files/nwpa 2004.pdf, U.S. DOE Office of Civilian Radioactive Waste Management, Washington, D.C, March 2004.

U.S. EPA, 2006, "Radiation Risk Assessment Software: CAP88 and CAP88 PC, http://www.epa.gov/radiation/assessment/CAP88/index.html, Web page accessed September 14, 2009.

U.S. NRC, 2005, 10CFR Part 63, Disposal of High-Level Radioactive Wastes in a Geologic Repository at Yucca Mountain, Nevada, sub-part 63.311, "Individual protection standard after permanent closure," U.S. Nuclear Regulatory Commission, Revision, November 18, 2005.

Wigeland, R. A., and T. H. Bauer, 2004, "Repository Benefits of AFCI Options," Argonne National Laboratory, ANL-AFCI-129, September 3, 2004.

Wigeland, R. A. et al., 2006, "Separations and Transmutation Criteria to Improve Utilization of a Geologic Repository,” Nuclear Technology, Vol. 154, pp. 95-106, April 2006.

Wigeland, R. A., T. H. Bauer, T. H. Fanning, and E. E. Morris, 2006, "Separations and Transmutation Criteria to Improve Utilization of a Geologic Repository,” Nucl. Tech. 154, p. 95, 2006. 